\title{
Segregation of Callosal and Association Pathways during Development in the Visual Cortex of the Primate
}

\author{
C. Meissirel, C. Dehay, M. Berland, ${ }^{a}$ and H. Kennedy \\ Vision et Motricité, INSERM U94, 69500 Bron, France
}

The segregation of callosal and association pathways in the developing visual cortex of the monkey was studied using the retrograde tracers fast blue and diamidino yellow. Quantitative analysis of the laminar distribution of labeled callosal and association neurons made it possible to reveal the shifting pattern of connections that characterizes the development of these two pathways.

In the adult, callosal neurons are restricted to supragranular layers, where they are concentrated at the bottom of layer 3. Association neurons are located both in infra- and supragranular layers. Supragranular layer association neurons are concentrated in layer 2 , with limited spread into layer 3 so that there is little overlap with callosal neurons.

In the immature brain, callosal neurons are characterized by a tangential distribution that is more widespread than in the adult, while their laminar distribution undergoes little developmental change. Association neurons show two types of changes in their laminar distribution: (1) in the early fetus, there is a large excess of association neurons in supragranular layers, the adult distribution being achieved some time after birth; and (2) during maturation there is a selective elimination of at least $50 \%$ of the projections originating from the lower part of layers $2 / 3$. Hence, the adult radial segregation of association and callosal pathways is achieved in part by regressive phenomena.

The developmental reduction of bihemispheric projections is largely independent of changes in the organization of association neurons. Quantitative analysis of the morphology and spatial location of neurons sending axon collaterals to both hemispheres suggests that they constitute a subset of callosal neurons and that their frequency is determined by factors that regulate directly this population.

These results are discussed with respect to the specification of visual cortical pathways during ontogenesis.

The formation of neural connections is governed by factors that are intrinsic to the developing cell components as well as by extrinsic or environmental factors including cellular interac-

\footnotetext{
Received Mar. 18, 1991; revised May 17, 1991; accepted May 29, 1991.

We thank Ghislaine Clain for expert assistance in animal breeding and Sandrine Richard and Noelle Boyer for their histological expertise. We are thankful to Jean Bullier and M. H. Giard for their comments on an earlier draft. Financial support was provided by an EEC Science operation grant (SC1*/CT91/0622).

Correspondence should be addressed to Henry Kennedy, Vision et Motricité, INSERM U94, 16 Avenue Doyen Lepine, 69500 Bron, France.

a Present address: Facultê de Médecine Lyon-Nord, Hopital Claude Bernard, Service de Gynécologie et Obstétrique, 69600 Oullins, France.
}

Copyright (C) 1991 Society for Neuroscience 0270-6474/91/113297-20\$05.00/0 tions. The degree to which the initial pattern of connections is more blurred in the immature cortex is important for understanding the scope of extrinsic control of the development of cortical connectivity. During corticogenesis, it is generally agreed that corticocortical connections exhibit a more widespread tangential pattern than in the adult (for recent reviews, see Innocenti, 1986; Finlay et al., 1987; Dehay et al., 1988a; O'Leary, 1989; Killackey, 1990). A changing laminar pattern of connections during normal development is altogether less well documented (Ivy and Killackey, 1981; Innocenti and Clarke, 1984; Olavarria and Van Sluyters, 1985; Price and Blakemore, 1985; Kennedy et al., 1989). This is somewhat paradoxical given that we have a fairly detailed idea of the relative contributions of intrinsic factors to the determination of the laminar organization of afferent connections (Caviness and Rakic, 1978; Jensen and Killackey, 1984; McConnell, 1988b).

The extent to which the juvenile radial pattern of cortical connectivity differs from that in the adult is facilitated when the mature configuration displays a high degree of order. Such a model is provided by the macaque visual cortex, where the laminar organization of cortical afferents is precisely defined. In the visual cortex of the adult monkey, callosal and association neurons show a remarkable degree of radial segregation. Although both pathways originate from supragranular layers, callosal neurons are located at the bottom of layers $2 / 3$, while association-projecting neurons are largely concentrated at the top of these layers (Kennedy and Bullier, 1985; Kennedy et al., 1986; Kennedy and Dehay, 1988; Meissirel et al., 1990). In the fetal monkey, simultaneous retrograde labeling of the parent neurons of callosal and association pathways in extrastriate cortex has shown that, although these pathways are centered at different levels within the supragranular layers, they show considerably more spatial overlap than in the adult (Meissirel et al., 1990).

Segregation of callosal and association pathways during development could be achieved by two processes. A decrease in the density of labeled neurons could result in each population of parent neurons being confined in the adult to those radial levels where they were most numerous in the fetus. In this case, the separation of these pathways during development would merely reflect the decrease in neuronal packing density that occurs in the expanding brain coupled with a random elimination of the association connections in supragranular layers produced in excess during corticogenesis (Kennedy et al., 1989). Alternatively, the segregation of these two pathways might be the consequence of a selective elimination of some connections and a stabilization of others. For the association pathway, this would mean that those association neurons in the fetus located 
in the callosally connected layers would be preferentially climinated while those located more superficially would be stabilized. To determine whether such a selective elimination of connections gives rise to the adult pattern, we have used quantitative methods to assess the precise laminar distribution during development of the parent neurons giving rise to callosal and association pathways.

In the adult, there is a small contingent of neurons in extrastriate cortex that have axon collaterals projecting to both cerebral hemispheres. This population is a remnant of an early developmental stage when bifurcating neurons are proportionally more numerous (Meissirel et al., 1990). It is not known whether bihemispheric-projecting neurons should be considered as callosal neurons with an ipsilateral-projecting collateral or whether they are part of the association pathway. To resolve this, we have morphologically distinguished association and callosal neurons and sought to determine which population is more closely related to bihemispheric-projecting neurons. By analyzing the changes in the proportions of bihemispheric-projecting neurons and relating these changes to the emerging segregation of callosal and association pathways, we have attempted to determine whether the selective elimination of bihemispheric projections is regulated by the refinement of the callosal or of the association pathway.

The present report sets out to quantify the extent to which selective elimination contributes to the exquisitely defined laminar organization of afferent pathways that characterizes the primate cortex. Determining whether selective elimination contributes to the segregation of callosal and association pathways is an important issue in the broader context relating developmental mechanisms in the primate to those described in nonprimate species. In a number of instances, neural development in the primate, at both cortical and subcortical levels, has been shown to depend far more on intrinsic mechanisms than is the case in other species (Dehay et al., 1988b; Chalupa and Lia, 1991). The present results indicate that major aspects of the radial segregation of callosal and association pathways are largely determined by intrinsic factors and that the late elimination of inappropriately placed connections plays only a secondary role in the emergence of the adult pattern.

\section{Materials and Methods}

We have investigated the callosal and associational pathways in three adult, one newborn, one 4.5-month-old, and two fetal cynomolgus monkeys (Macaca irus). Association pathways alone were investigated in one fetus, two neonates, and one adult (Table 1). The fetuses, obtained from timed pregnant monkeys, were injected with fluorescent dyes on embryonic day 122 (E122), E130, and E135, and the brains were processed for histological examination 10-11 d later (Table 1).

Anesthesia and surgery. Following premedication with atropine (1.25 $\mathrm{mg}, \mathrm{i} . \mathrm{m}$.) and dexamethasone ( $4 \mathrm{mg}$, i.m.), the monkeys were prepared for surgery under ketamine hydrochloride $(20 \mathrm{mg} / \mathrm{kg}$, i.m.) and chlorpromazine $(2 \mathrm{mg} / \mathrm{kg}$, i.m.). After intubation, anesthesia was continued with halothane in an $\mathrm{N}_{2} \mathrm{O} / \mathrm{O}_{2}(70: 30)$ mixture. The heart rate was monitored, and artificial respiration was adjusted to maintain the end-tidal $\mathrm{CO}_{2}$ at $4.5-5 \%$. The rectal temperature was monitored and maintained at $37^{\circ} \mathrm{C}$. In the pregnant monkeys, a midline abdominal incision allowed uterotomy to be performed and the fetal head to be exposed. Craniotomy was performed over the posterior part of the brain so as to reveal the occipital, parietal, and temporal lobes of one hemisphere. Contralaterally, a smaller craniotomy was made over the lateral part of the operculum.

Injection of retrograde tracers. Injections of fluorescent tracers were made either directly by Hamilton syringes or by Hamilton syringes sealed to micropipettes.

Labeling of callosal afferents was obtained either by restricted (animals
BB37, M24) or extensive (BB34, BB43, BB50, M42, M44) injections of one hemisphere (Table 1). Restricted injections in extrastriate cortex were carried out by a single injection of diamidino yellow (DY; BB37) or several injections of fast blue (FB; M24), 2-3 mm down the lateral part of the posterior bank of the lunate sulcus, where the central visual field in area V2 is located (Gattass et al., 1981). As the needle was withdrawn, $0.05 \mu \mathrm{l}$ of dye was injected per $\mathrm{mm}$. Extensive injections were made by injecting a wide expanse of extrastriate cortex and the adjacent callosally connected strip of area 17 (Kennedy et al., 1986) with fast blue at regular 2-3 mm intervals. These injections covered a large extent of the operculum, the posterior and anterior banks of the lunate sulcus, the prelunate gyrus, and the posterior bank of the superior temporal sulcus. The extensive injection in M42, but not in BB34, also involved area $\mathrm{V} 2$ on the ventral cortical surface as well as two $1.5-\mathrm{mm}-$ long injections in the rostral end of the corpus callosum.

Association afferents were labeled by an injection of the complementary fluorescent dye in area $\mathrm{Vl}$ of the hemisphere contralateral to the injection of callosal terminals by restricted (BB34, BB37, BB50, M42, M44) or extensive (BB43, M24) injections. One fetus (BB38), two neonates (BB18, BB22), and one adult (M37) received uniquely restricted area 17 injections. In all cases, area 17 injections were made at a shallow angle to the cortical surface so that the injection spanned $3-5 \mathrm{~mm}$ in the cortical gray matter approximately $5 \mathrm{~mm}$ parallel to the lateral part of the lunate sulcus where the representation of the central visual field is located (Gattass et al., 1981). Restricted area V1 injections correspond to a single elongated injection parallel to the $\mathrm{V} 1 / \mathrm{V} 2$ horder. Extensive injections in V1 consisted of three or four parallel injection tracks separated by $1-1.5 \mathrm{~mm}$.

Following injections, bone flaps were closed and the scalp stitched back in position. For prenatal material, the fetus was replaced in the uterus and incisions were closed using routine procedures. In the case of fetal injections, the mother received postoperative medicalion consisting of a muscular relaxant (Duvadilan) and analgesic (Visceralgine).

Histological processing. Fetuses were delivered by cesarian section after a $10-11 \mathrm{~d}$ survival period. This was found to be optimal for both cortical pathways since it led to strong levels of labeling with no detectable signs of leakage of the dye from retrogradely labeled cells. Animals were deeply anesthetized before being perfused transcardially with $200 \mathrm{ml}$ of $2.7 \%$ saline, followed by $1-3$ liters of $12 \%$ paraformaldehyde in $0.1 \mathrm{~m}$ phosphate buffer, $0.5-1$ liter of $8 \%$ sucrose, $0.5-1$ liter of $20 \%$ sucrose, and $0.5-1$ liter of $30 \%$ sucrose in phosphate buffer. Brains were immediately removed and blocked, and parasaggital or horizontal 40$\mu \mathrm{m}$-thick sections were cut on a freezing microtome. One in three sections was kept and mounted from saline onto gelatinized slides.

Examination of material. Sections were observed in UV light with oil-immersion objectives using a Leitz fluorescence microscope equipped with a D-filter set $(355-425 \mathrm{~nm})$. The properties and description of neurons labeled with diamidino yellow and/or fast blue can be found in a publication by Kuypers et al. (1980). Neurons labeled by fast blue exhibit a blue coloration in their cytoplasm. Neurons labeled by diamidino yellow exhibit a yellow nucleus. Double-labeled neurons show simultaneously a bright yellow nucleus and blue cytoplasm. An $x-y$ plotter electronically coupled to the microscope stage was used to trace out sections and to record the positions of labeled neurons.

In order to estimate neuron size, we measured the nucleus diameter, which is known to be a related parameter (Bok, 1959). The fluorescentstaincd nuclei werc clcarly labcled and were traced out with a $50 x$ objective and a drawing tube. Areas were obtained with a graphic tablet interfaced with an IBM personal computer.

After the positions and dimensions of labeled neurons had been determined, sections were counterstained for Nissl substance with cresyl violet. Counterstained sections were projected on to charts of labeled neurons so as to relate the positions of labeled neurons to histological borders.

Terminology. The areal extent of a population of retrogradely labeled cells in one cortical area resulting from an injection in another area is referred to as a projection zone. Each injection leads to the labeling of neurons in a circumscribed volume of cortex. When the volumes from two simultaneous injections coincide, we define the common territory as the overlap zone. A more detailed description of the definition and significance of the overlap zone can be found clscwhcre (Bullicr ct al., 1984a,b; Kennedy and Bullier, 1985; Perkel et al., 1986). Neurons labeled by the injection in area 17 are referred to as association neurons, and neurons labeled by the injection in the contralateral hemisphere are referred to as callosal neurons. 


\begin{tabular}{|c|c|c|c|c|}
\hline Animals & Age at injection & $\begin{array}{l}\text { Survival } \\
\text { time (d) }\end{array}$ & $\begin{array}{l}\text { Area V1 } \\
\text { injection }\end{array}$ & $\begin{array}{l}\text { Extrastriate } \\
\text { injection }\end{array}$ \\
\hline BB34 & E122 & 11 & DY $\mathbf{r}$ & FB e \\
\hline \multirow[t]{4}{*}{ BB38 } & E130 & 11 & DY $(\mathbf{R H}) \mathrm{r}$ & - \\
\hline & & & $\mathrm{FB}(\mathrm{RH}) \mathrm{r}$ & - \\
\hline & & & DY $(\mathrm{LH}) \mathrm{r}$ & - \\
\hline & & & $\mathrm{FB}(\mathrm{LH}) \mathrm{r}$ & - \\
\hline ВВ37 & E135 & 10 & FB r & $\mathrm{DY} \mathrm{r}$ \\
\hline \multirow[t]{4}{*}{ BB 18} & P1 & 10 & DY $(\mathrm{RH}) \mathrm{r}$ & - \\
\hline & & & $\mathrm{FB}(\mathrm{RH}) \mathrm{r}$ & - \\
\hline & & & $\mathrm{DY}(\mathrm{LH}) \mathbf{r}$ & - \\
\hline & & & FB (LH) r & - \\
\hline \multirow[t]{4}{*}{ BB22 } & P3 & 16 & $\mathrm{DY}(\mathrm{RH}) \mathrm{r}$ & - \\
\hline & & & $\mathrm{FB}(\mathrm{RH}) \mathrm{r}$ & - \\
\hline & & & $\mathrm{DY}(\mathrm{LH}) \mathrm{r}$ & - \\
\hline & & & FB $(\mathrm{LH}) \mathrm{r}$ & - \\
\hline BB43 & P7 & 10 & DY e & FB e \\
\hline BB50 & 4.5 Months & 11 & DY r & FB e \\
\hline M24 & Adult & 11 & DYe & FB r \\
\hline \multirow[t]{4}{*}{ M37 } & Adult & 14 & DY $(\mathrm{RH}) \mathrm{r}$ & - \\
\hline & & & $\mathrm{FB}(\mathrm{RH}) \mathrm{r}$ & - \\
\hline & & & $\mathrm{DY}(\mathrm{LH}) \mathrm{r}$ & - \\
\hline & & & $\mathrm{FB}(\mathrm{LH}) \mathrm{r}$ & - \\
\hline M42 & Adult & 11 & DY $\mathbf{r}$ & FB e \\
\hline M44 & Adult & 13 & DY r & $\mathrm{FB} \mathrm{e}$ \\
\hline
\end{tabular}

r, Restricted injection; e, extensive injection (see Materials and Methods). RH, right hemisphere; LH, left hemisphere. E, embryonic day; P, postnatal day. FB, fast blue; DY, diamidino yellow.

\section{Results}

In the fetus, the use of fluorescent dyes FB and DY gave excellent retrograde labeling, and with appropriate survival times doublelabeled neurons were readily detected. Labeled dendrites were clearly visible in FB-positive neurons. The labeled apical dendrites typically showed a wavy appearance not observed in the adult (Fig. 1).

\section{Injection sites}

A critical aspect of the present study is the comparison of the laminar distribution of retrogradely labeled association neurons following injections at different ages. This made it important to carry out injections in a stereotyped fashion (see Materials and Methods) so as to avoid spurious differences in labeling due to differences in the laminar location of injection sites. Typically, injection sites spanned all cortical layers (Fig. 2). Reconstructions of injection sitcs showcd that the $3-5 \mathrm{~mm}$ of the needle tracks traversed the cortical layers without involving the underlying white matter (Fig. 2). Surrounding the needle track is a region of dense extracellular coloration that corresponds to the uptake zone of the dyes FB and DY (Fig. 2) (Keizer et al., 1983; Bullier et al., 1984a; Kennedy and Bullier, 1985; Condé, 1987; Ferrer et al., 1988).

\section{Areal distribution of callosal and association projecting neurons}

In the adult, callosal neurons were found in discrete cortical regions situated on the ventral and dorsal bordcrs of arca 17, in the fundus and anterior bank of the lunate sulcus, and in a restricted region of the posterior bank of the superior temporal sulcus (Fig. 3A). In the posterior bank of the lunate sulcus (area V2) callosal neurons were not evenly distributed but showed some degree of clustering (Kennedy et al., 1986). Extensive injections led to higher numbers of labeled cells per section in rostral regions than did restricted injections (see Table 3).

In the neonate, the tangential distribution of callosal neurons appeared similar to that in the adult (Dehay et al., 1986). Prenatally, however, the areal distribution of callosal neurons was different from that in the adult. In the fetus at E133, callosal

Figure 1. Retrograde labeling with fluorescent dyes in fetal monkey (E122). A, Area V2. In the upper layers can be seen the two populations of single-labeled cells. In the lower layers, only labeled area 17 afferents are found. Note the absence of labeled neurons in layer 4 . $B$, Posterior bank of the superior temporal sulcus (STS). The two populations of neurons in the superficial layers show some spatial overlap. Note the undulating appearance of the apical dendrite that is characteristic of fetal material. $C$, A double-labeled neuron located at the bottom of layer 3 in STS. Note the large size of the nucleus and the relatively sparse cytoplasm.

Figure 2. Reconstruction of DY injection site in an adult $(A)$ and fetus $(B)$. The inserts show the level of the horizontal sections taken at 1200 $\mu \mathrm{m}$ intervals (small numbers dorsal). The injection site shows a black center that corresponds to a crystal of the dye. The line around the crystal corresponds to the limit of the uptake zone (see Materials and Methods). Small dots show the extent of intrinsic labeling, which can be seen to be limited in layer 4 . In both adult and fetus, the pickup zone involved both supra- and infragranular layers. The photomicrographs show the injection site in the adult (left) and fetus (right). The numbered white horizontal bars indicate the bottom limit of layer 4. wm, white matter. 


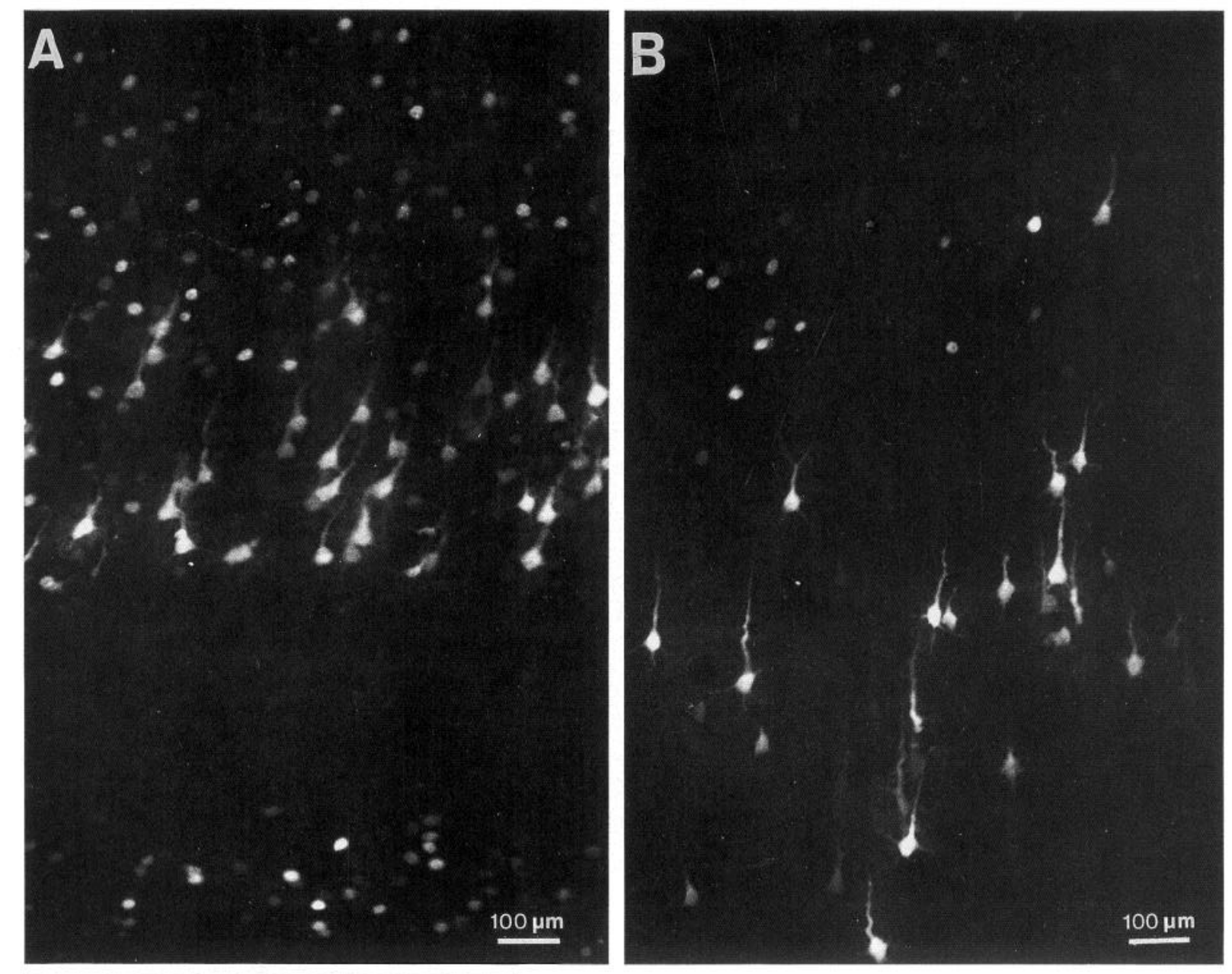

C 


\section{ADULT (M37)}
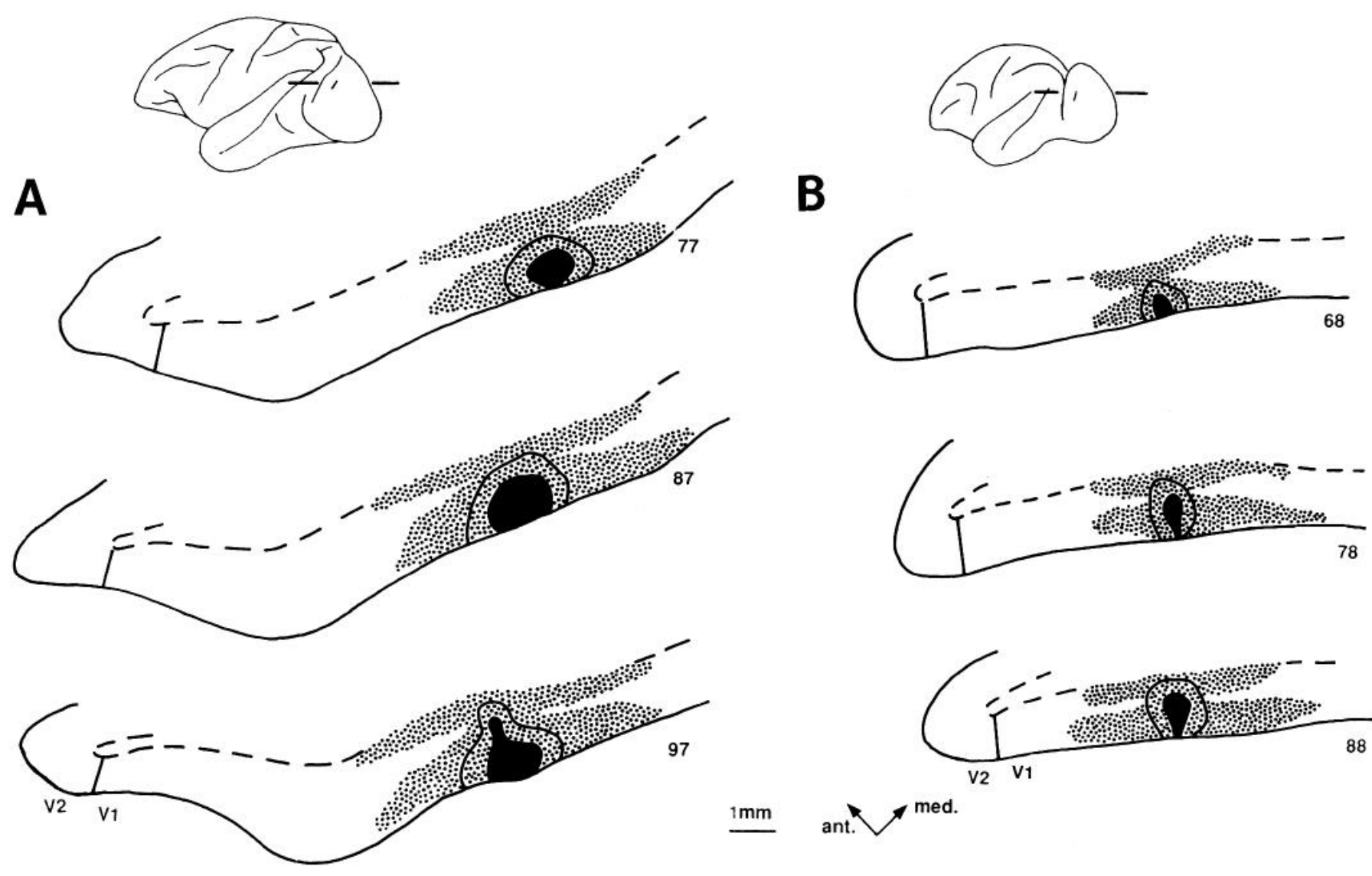

$1 \mathrm{~mm}$ ant.
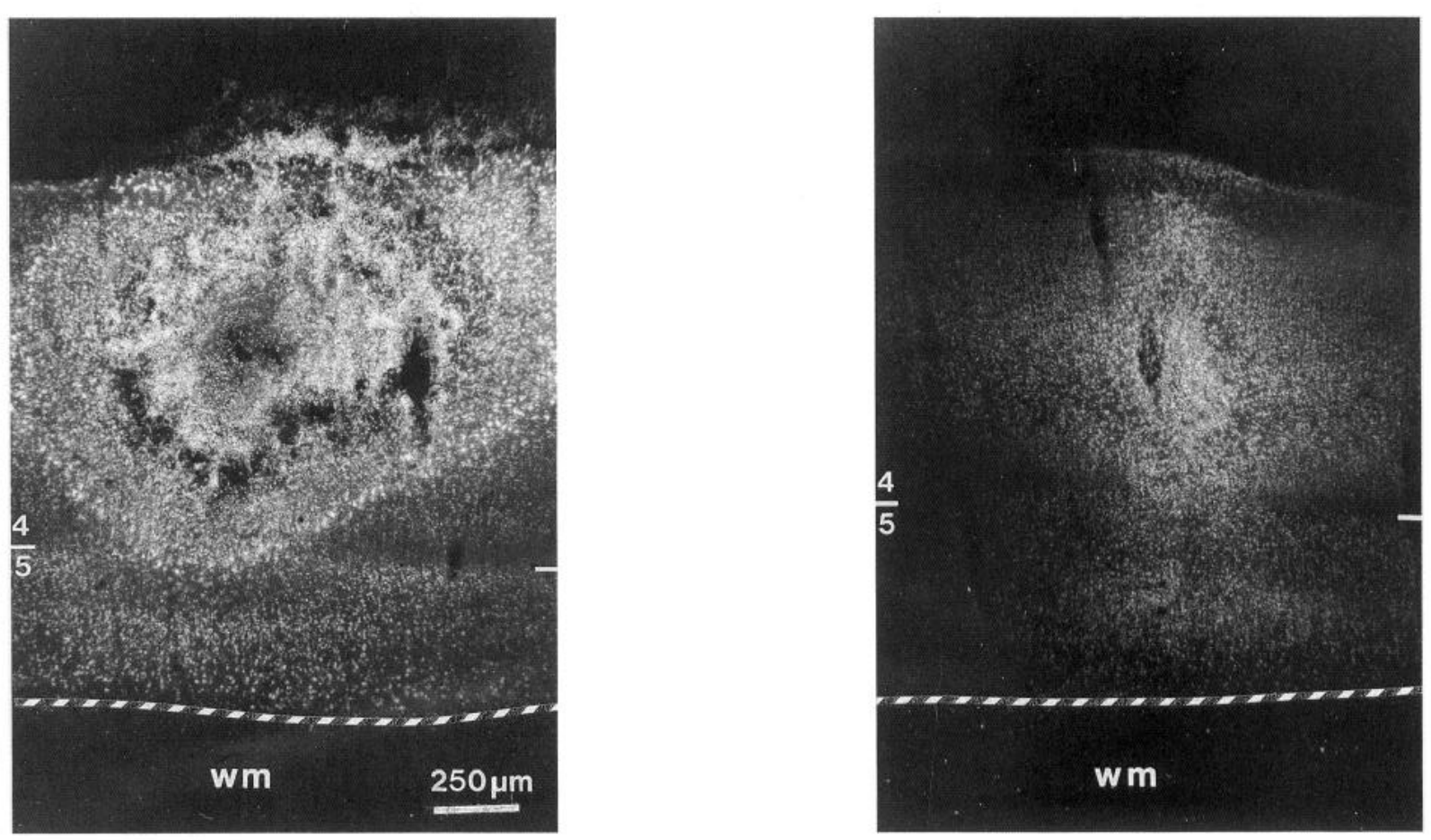


\section{A ADULT (M 42)}

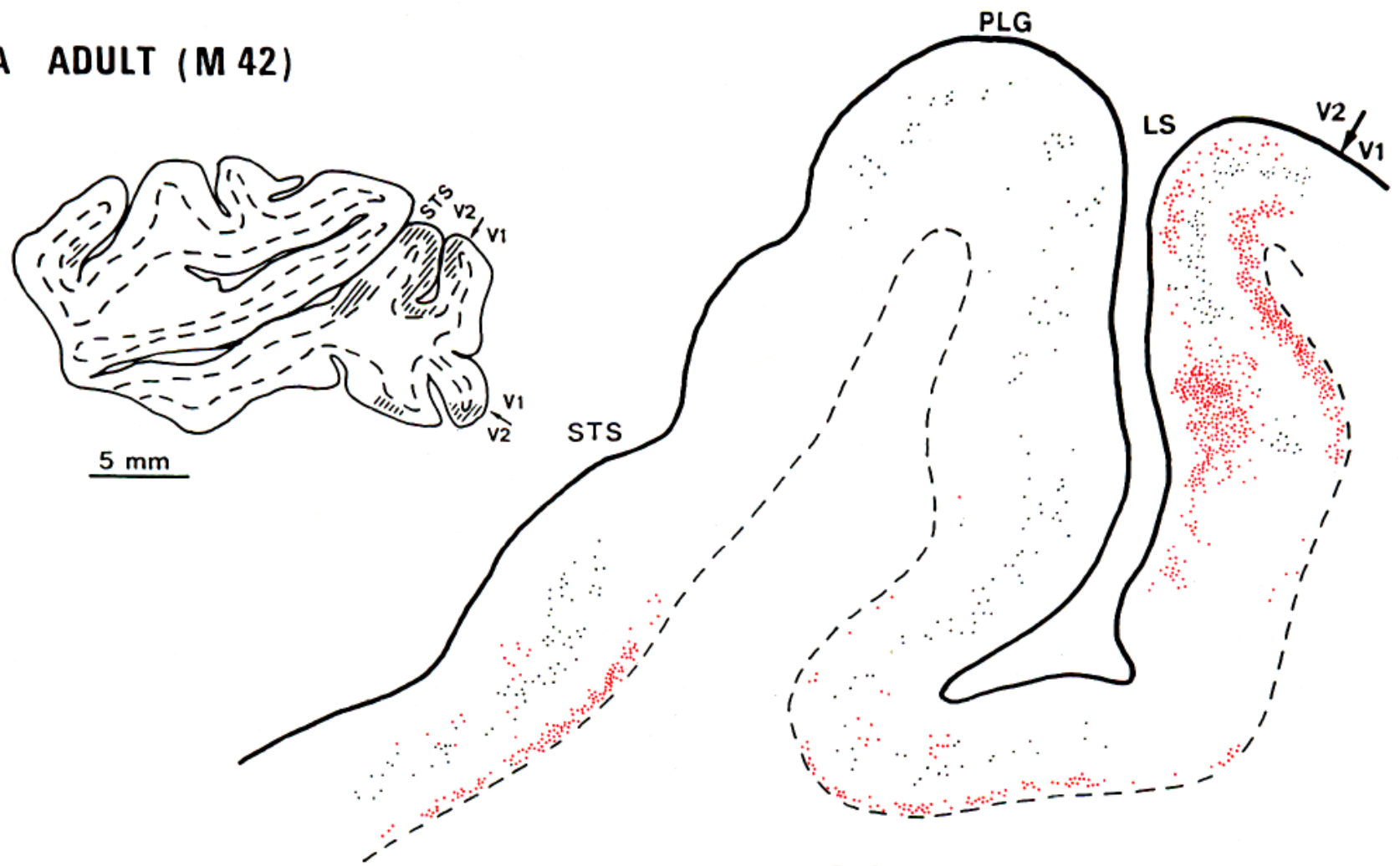

\section{B FETUS (E 122)}

I: Fast Blue

:S Diamidino Yellow

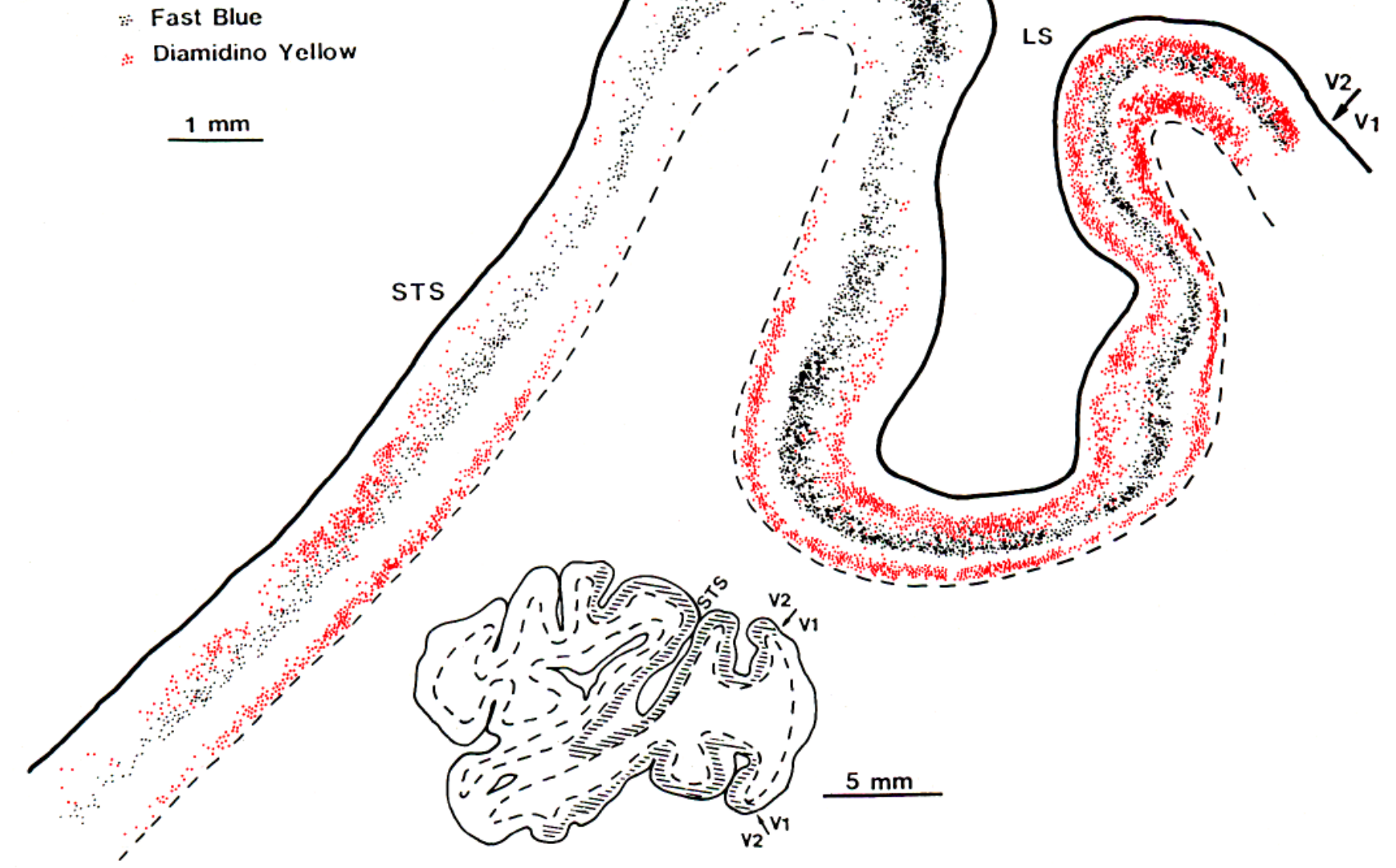


neurons extended rostrally from the border of area $\mathrm{V} 1$ in an uninterrupted band (Fig. $3 B$ ). On the dorsal cortical surface, the continuous band of labeled neurons reached as far as the anterior bank of the superior temporal sulcus and ventrally as far as the inferior temporal sulcus. No hint of clustering of callosal neurons was detected in area V2 of prenatal cases after either extensive or restricted contralateral injections.

Association neurons projecting to area 17 in the adult were located in the posterior and anterior banks of the lunate sulcus, the prelunate gyrus, and the posterior bank of the superior temporal sulcus (Kennedy and Bullier, 1985; Perkel et al., 1986). In neonatal and prenatal animals, the overall areal distribution of neurons projecting to area 17 was similar to that in the adult, although there was a tendency for the labeled neurons to cover a greater proportion of extrastriate cortex in the prenatal cases. This can be seen in Figure 3 where, in the fetus, neurons projecting to area 17 are in regions between major zones of projection.

\section{Laminar distribution of callosal and association projecting neurons}

In the fetuses, the cortex was thinner and cell density higher than in the adult. Despite these immature aspects of the fetal cortex, cytoarchitectonics were clear so that layers $2 / 3,4,5$, and 6 could be distinguished as well as the borders of area 17 . Densities of labeled neurons were also higher than in the adult. Despite the presence of numerous labeled association neurons in infragranular layers, no labeled neurons were found in the underlying white matter except in the vicinity of the injection site in area 17. This did not appear to be a distinctive feature in the immature brain since in the adults labeled neurons were also occasionally observed in the white matter in the vicinity of the injection site. In the hemisphere contralateral to the massive extrastriate injections, no labeled callosal neurons were found in the subplate zone.

Callosal pathway. In adult extrastriate visual cortex, callosal neurons were virtually exclusively located in a narrow band in supragranular layers except in the prelunate gyrus, where they were occasionally found to originate from infragranular layers.

At the fetal stages examined as well as in the newborn, callosal neurons were found in a relatively tight band in supragranular layers (Fig. 3B). Callosal neurons in infragranular layers did not appear to be proportionally more numerous than in the adult. As in the adult, callosal neurons in infragranular layers were chiefly located in the prelunate gyrus and the upper part of the anterior bank of the lunate sulcus.

To conclude, at all ages the laminar origin of callosal neurons was remarkably uniform and showed minimal variation across extrastriate cortex (Fig. 3; see also Figs. 5-7). This made the quantification of any developmental shift in the radial pattern of callosal neurons relatively straightforward.
Association pathway. It has becn shown that labeled arca 17 afferents in a cortical projection zone are not distributed in a uniform fashion across the cortex but instead show periodic variations in density. Therefore, so as to characterize the laminar distribution of a particular set of connections, it is necessary to estimate the total number of labeled neurons in each of the cortical laminae from counts made at regular intervals throughout the projection zone.

In the adult extrastriate cortex, the proportion of area 17 projecting neurons in supra- and infragranular layers is a characteristic feature of each particular cortical region (Kennedy et al., 1989). Thus, area 17-projecting neurons in area V2 are distributed equally among supra- and infragranular layers, and the more rostral cortical areas display progressively fewer area 17-projecting neurons in supragranular layers. In the posterior bank of the superior temporal sulcus, they constitute only 2$5 \%$ of the total number of labcled association-projecting neurons. (Kennedy et al., 1989).

During postnatal development, association neurons undergo a change in their laminar distribution. In the neonate, higher proportions of area 17-projecting neurons are located in supragranular layers than in the adult (Kennedy et al., 1989). The present results show that this phenomenon is more pronounced in the fetus. To compare the laminar distribution of labeled association neurons, we have plotted the number of labeled neurons in the supra- and infragranular layers at regular intervals throughout the entire projection zone. This is illustrated in two representative adults and one fetus in Figure 4, where the abscissa shows the distance through the projection zone and the ordinate shows the number of infragranular and supragranular layer neurons per section. In the adult, the numbers of labeled infragranular layer neurons are higher than labeled supragranular layer neurons, except in area V2, where similar proportions are found in both sets of layers. In the fetus, the relationship is inversed, and numbers of supragranular layer neurons are higher than those of the infragranular layer neurons in all extrastriate areas including area $\mathrm{V} 2$.

To obtain an overall estimation of the changes in laminar distribution of area 17-projecting neurons in the fetuses and adults, we have calculated the percentage of labeled supragranular layer neurons per animal (the number of labeled supragranular layer neurons divided by the total number of labeled neurons in both sets of layers). Counts were made at $600 \mu \mathrm{m}$ intervals throughout the projection zone. In area V2 of the fetuses, the range of values was $60-84 \%$, compared to $43-53 \%$ in the adults. In the posterior bank of the superior temporal sulcus in the fetus, $60 \%$ of labeled area 17 afferent neurons were located in upper layers, compared to $2-7 \%$ in the adult. As the fetal values are not included in the range reported for the neonatc, the changes in laminar distribution previously reported in the neonate (Kennedy et al., 1989) are therefore the tail end of a process commenced prenatally.

\footnotetext{
Figure 3. Areal distribution of neurons projecting to the contralateral hemisphere (callosal-projecting neurons, black dots) and neurons projecting to ipsilateral area 17 (association-projecting neurons, red dots) following a massive contralateral FB injection and a restricted ipsilateral DY injection in area 17. $A$. Adult monkey. Association neurons are found principally in infragranular layers. Those association neurons that are found in supragranular layers tend to be superficial to callosal-projecting neurons. Despite some overlap of the populations of callosal- and area 17-projecting neurons, double-labeled neurons were extremely rare. B, E122 fetal monkey. Area 17 is devoid of callosal-projecting neurons, while labeled association and callosal neurons form a continuous swath in extrastriate cortex. This figure shows that callosal neurons show little change in their radial distribution during development while association neurons are more numerous in supragranular layers in the fetus, where they overlap extensively with callosal neurons.
} 


\section{ADULT}

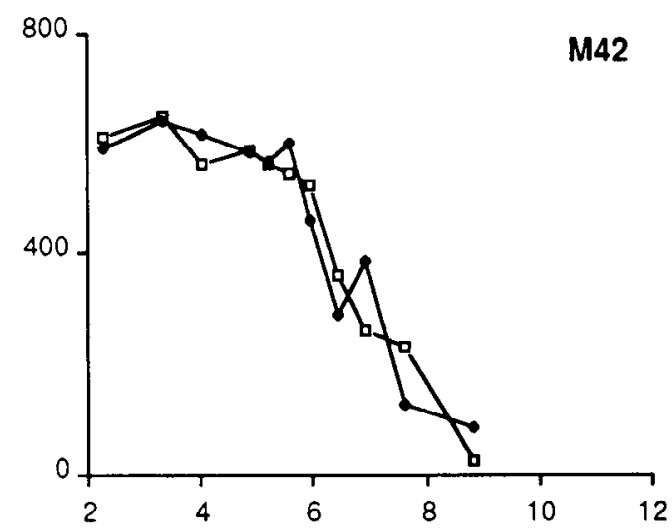

V2

FETUS

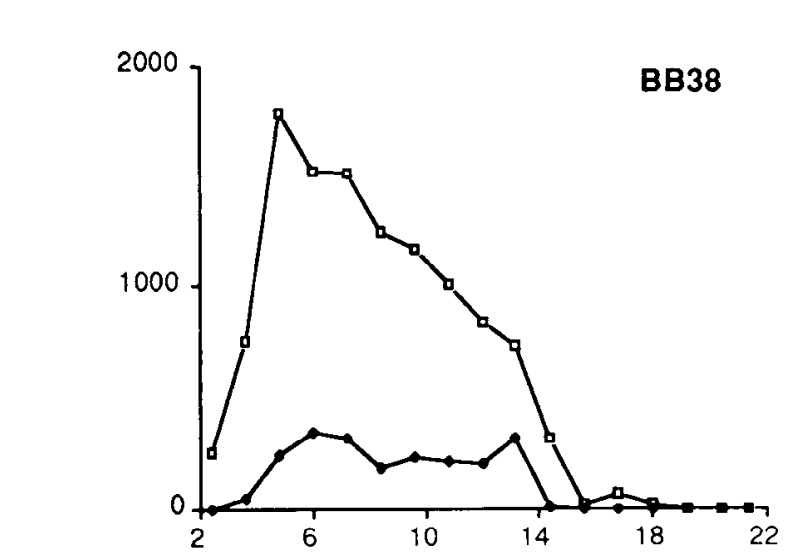

ABLS
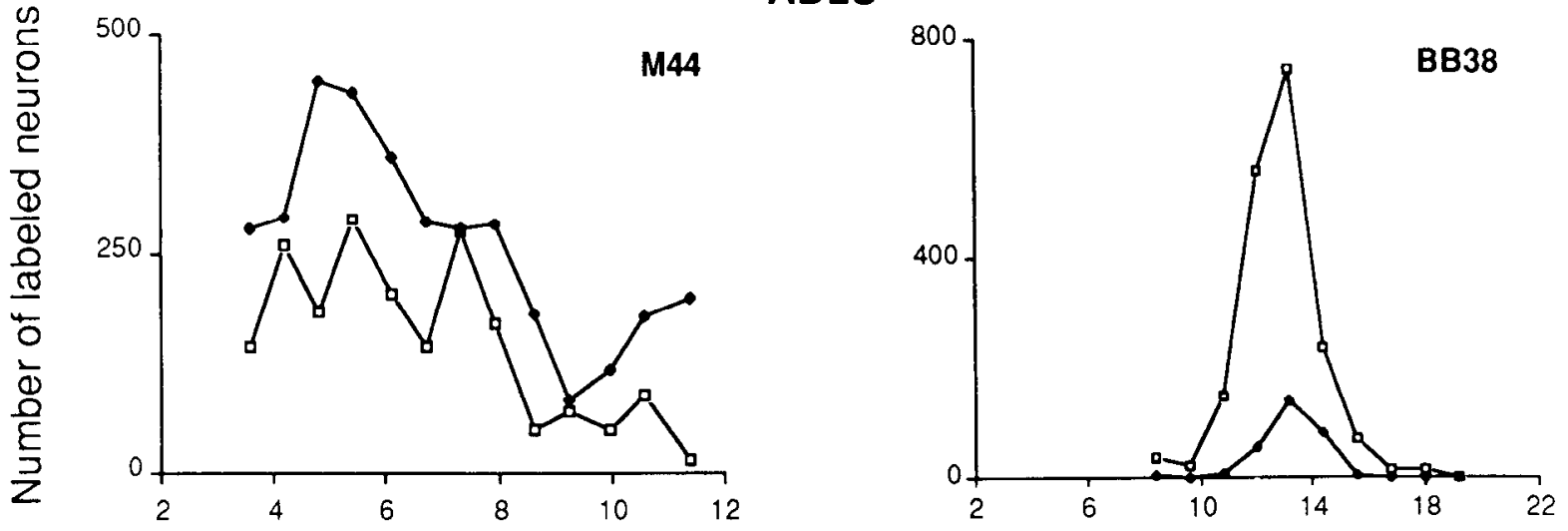

STS

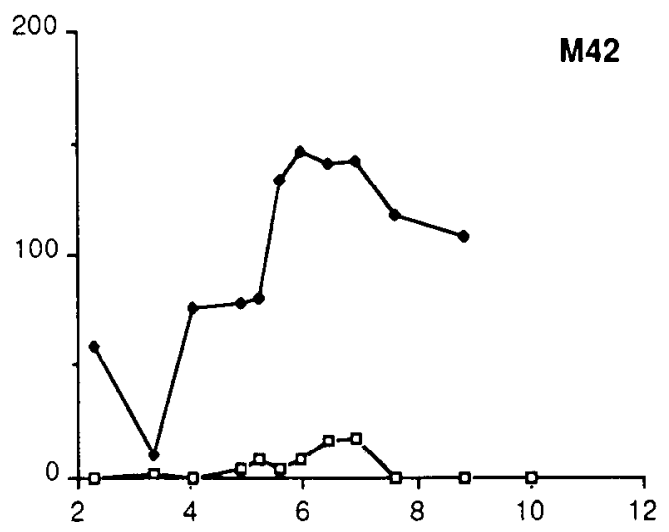

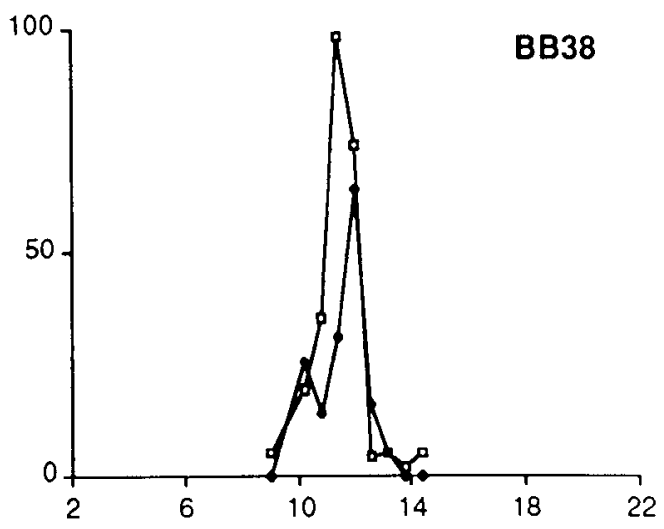

- supragranular - infragranular

Figure 4. Numbers of labeled area 17-projecting neurons per section throughout the projection zone in supragranular layers (open circles) and infragranular layers (solid circles) in adult (left) and the E130 fetus (right). Ordinates, numbers of neurons per section; abscissas, distance in millimeters through the projection zone. In the adult, the numbers of neurons in both sets of layers are very similar in area V2. In the anterior bank of the lunate sulcus $(A B L S)$ and in $S T S$, labeled neurons become proportionally less numerous in supragranular layers. In the fetus, supragranular layer neurons predominate in all areas, and in STS this population constitutes a transient projection since it almost cntircly disappcars in the adult. 


\section{AREA V2}

\section{A ADULT ( M 42)}

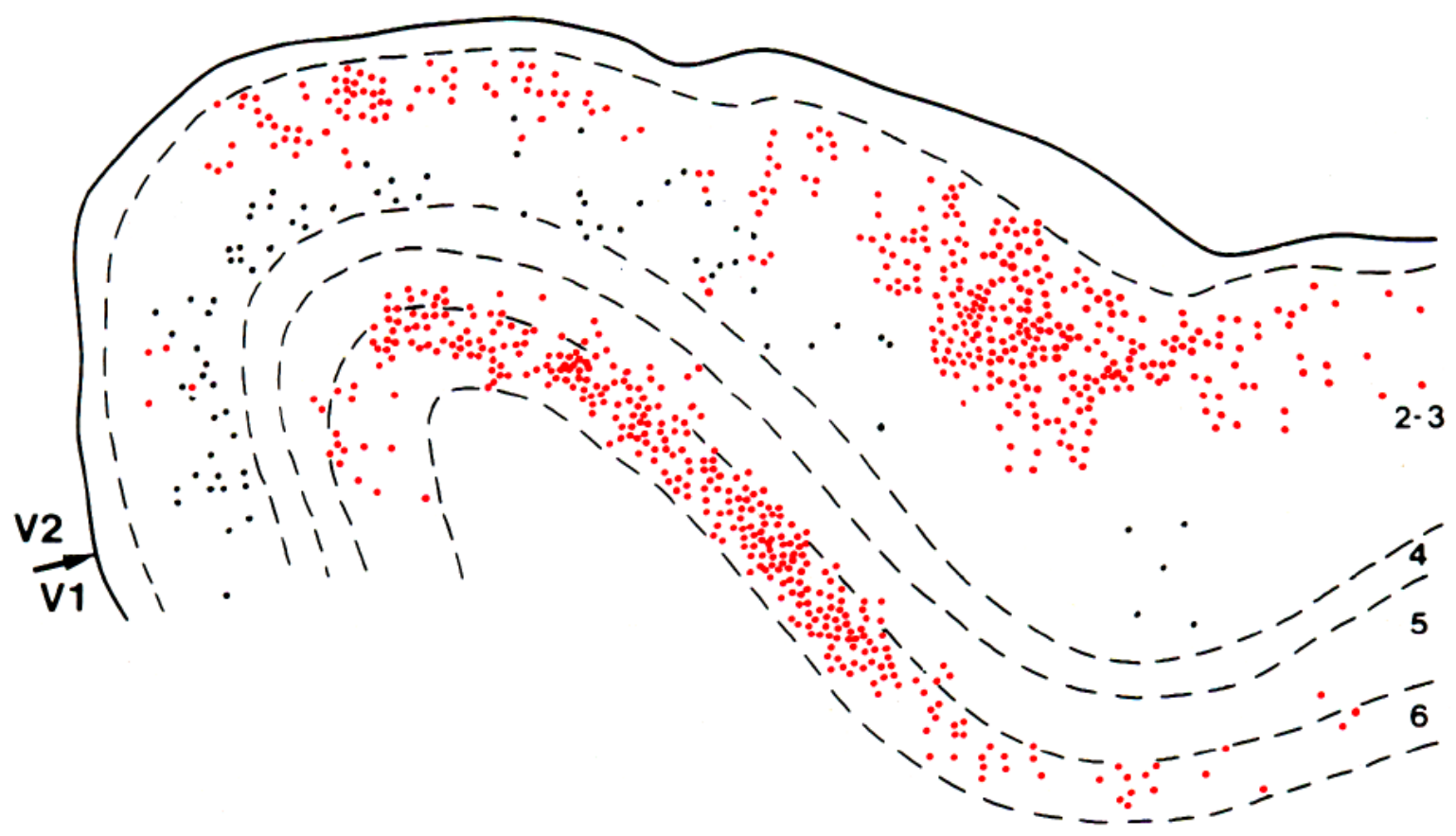

\section{$B$ FETUS ( E 122)}

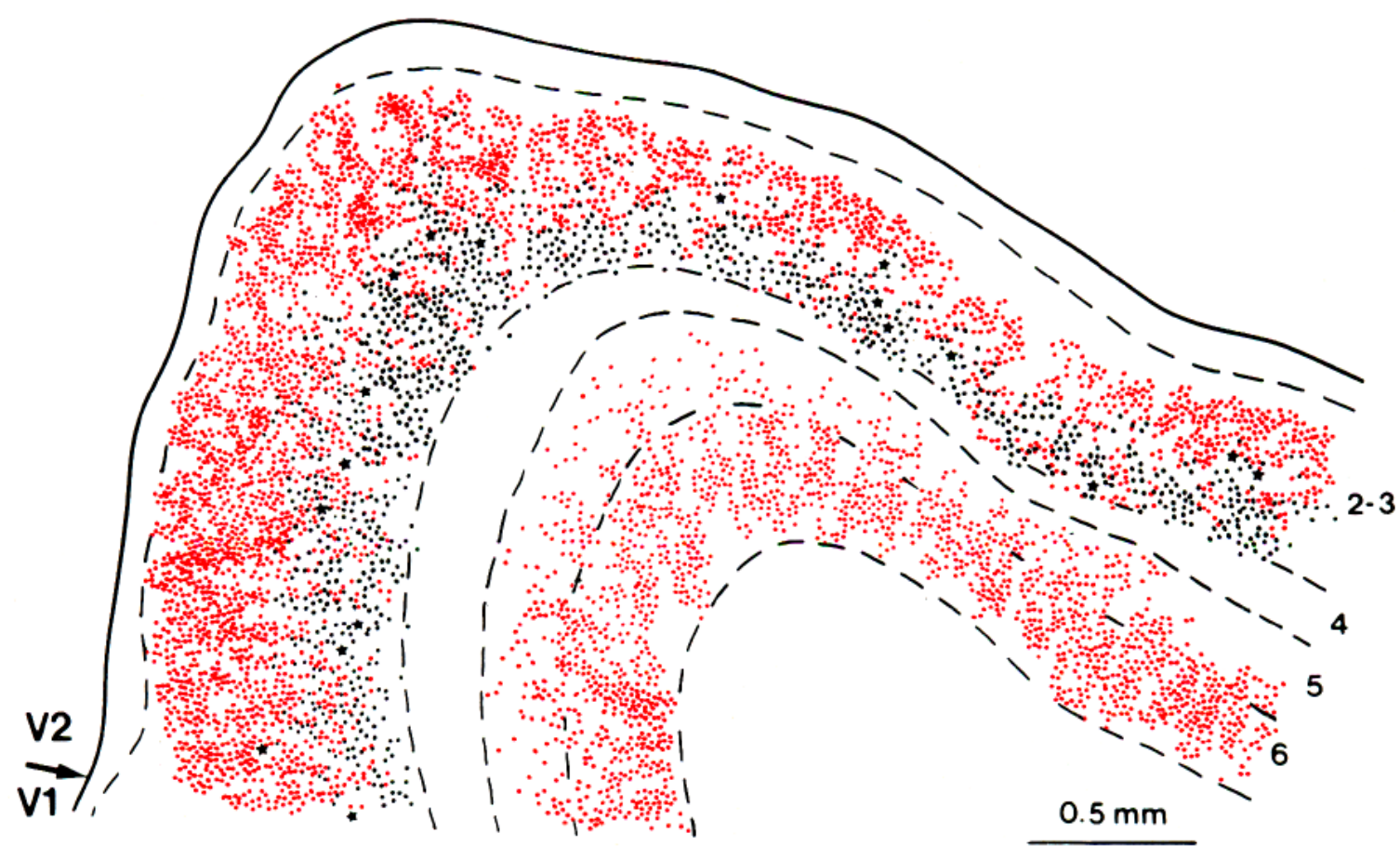

Figure 5. Distribution of callosal (black dots) and area 17 (red dots) projecting neurons in area V2 in the adult (top) and E122 fetus (bottom) in sections showing peak numbers of labeled association neurons. The density of labeled neurons is highest in the fetus, where a number of doublelabeled neurons (stars) are found. Despite high densities of labeled neurons, there is some degree of segregation of callosal and association pathways in the supragranular layers. In the fetus, the density of labeled area 17-projecting neurons decreases with increasing depth so that in the region where callosal-projecting neurons are found they are clearly less abundant than in the upper part of layer 2. Double-labeled neurons occur in a narrow band somewhat below the uppermost labeled callosal-projecting neurons. 


\section{A B LS}

\section{A ADULT (M44)}

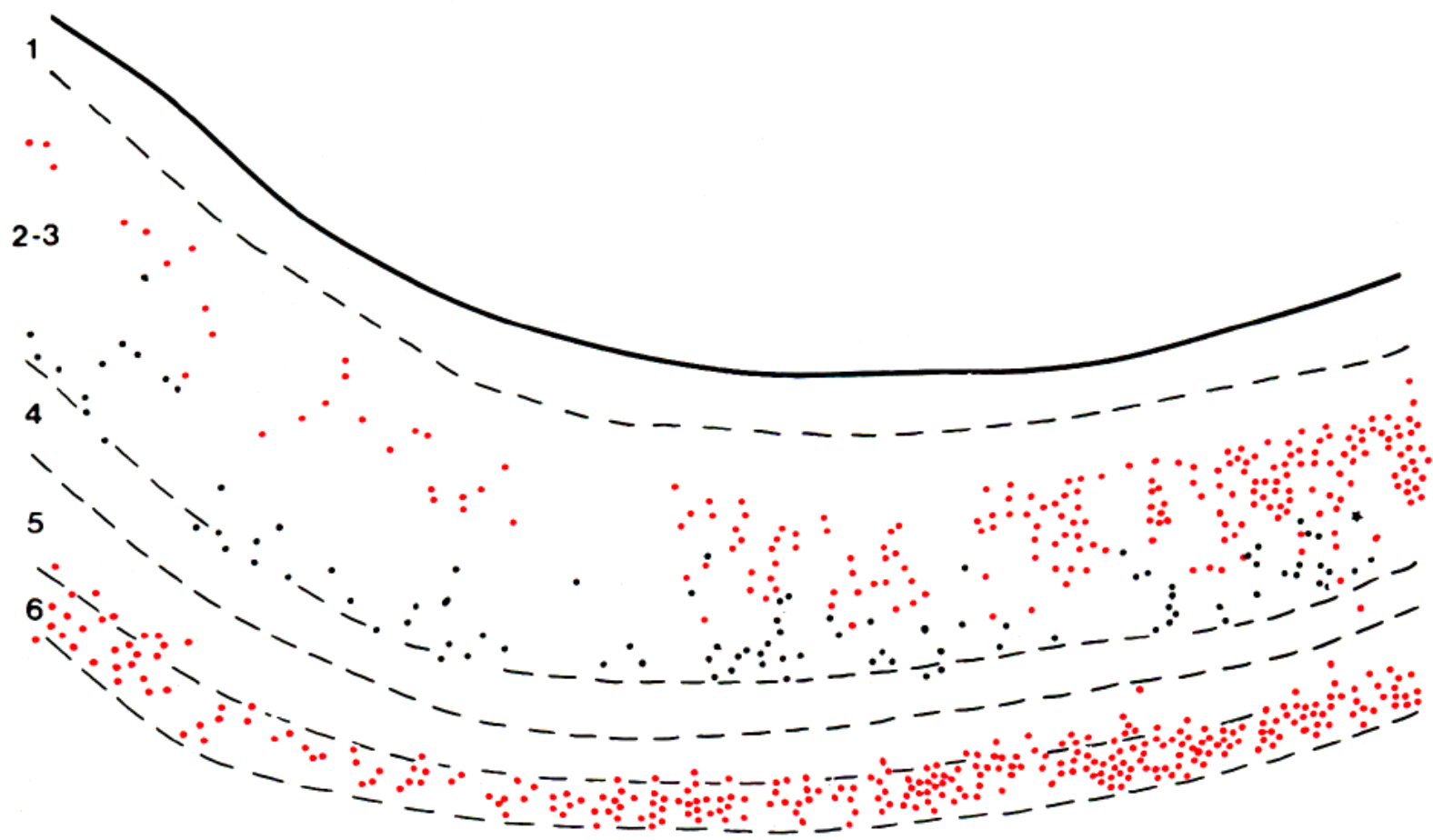

\section{B FETUS (E 122)}

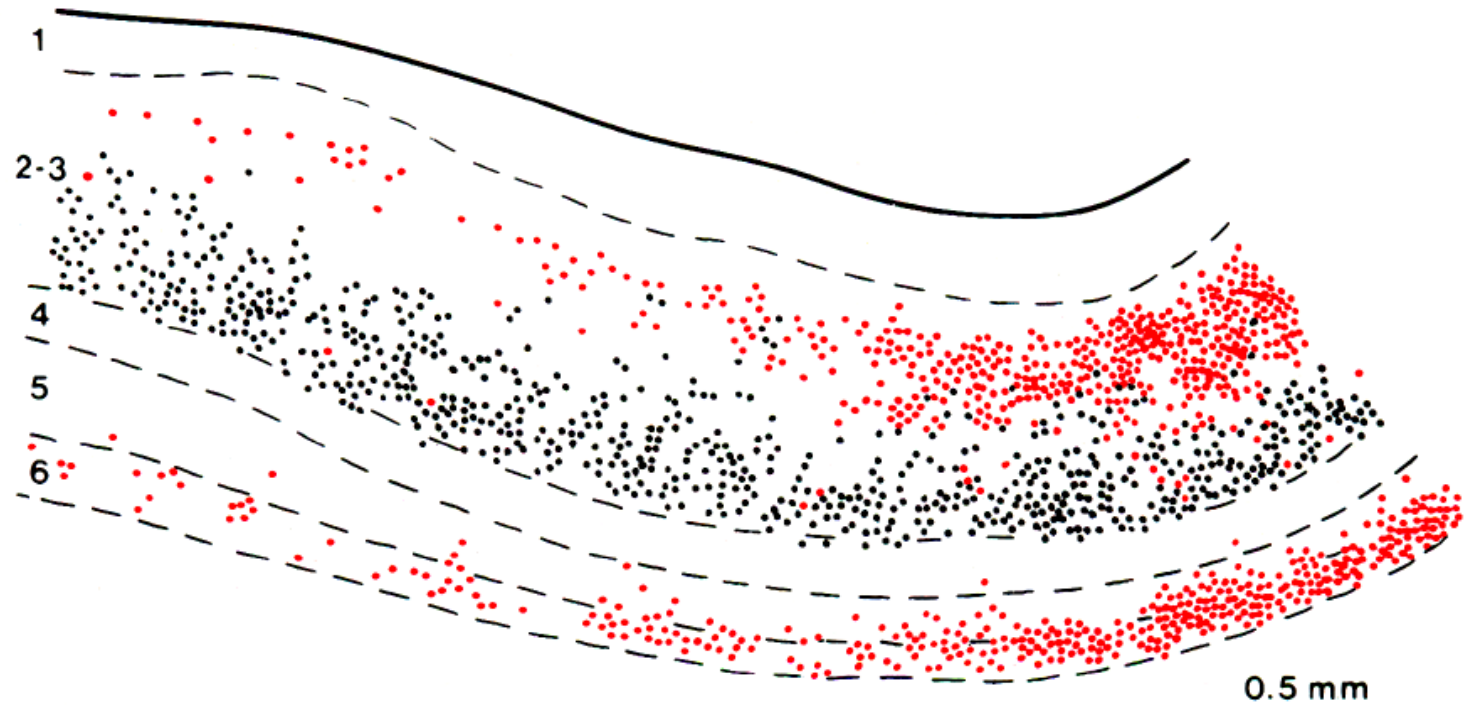

Figure 6. Callosal- and area 17-projecting neurons in the anterior bank of the lunate sulcus (ABLS, area V3) in the adult (top) and E122 fetus (bottom). Section has peak values of labeled association neurons. Note that despite a drop in density of area 17 afferents with regard to area V2 (shown in Fig. 5), there is still overlap of callosal- and association-projecting neurons. Symbols are as in Figure 5.

Analysis of the segregation of callosal- and association-projecting neurons in supragranular layers

The simultaneous labeling of callosal and association neurons made it possible to investigate directly the degree of radial separation within the supragranular layers of these two pathways.
Throughout extrastriate cortex in the fetus and in the adult, callosal neurons were located deeper in the supragranular layers (chiefly in layer 3 ) than were area 17-projecting neurons (chiefly in layer 2). Surprisingly, despite the greater proportion of supragranular layer area 17-projecting neurons in the immature brain, there was a remarkable degree of radial segregation of callosal and association neurons during development. 


\section{AREA STS}

\section{A ADULT (M 42)}

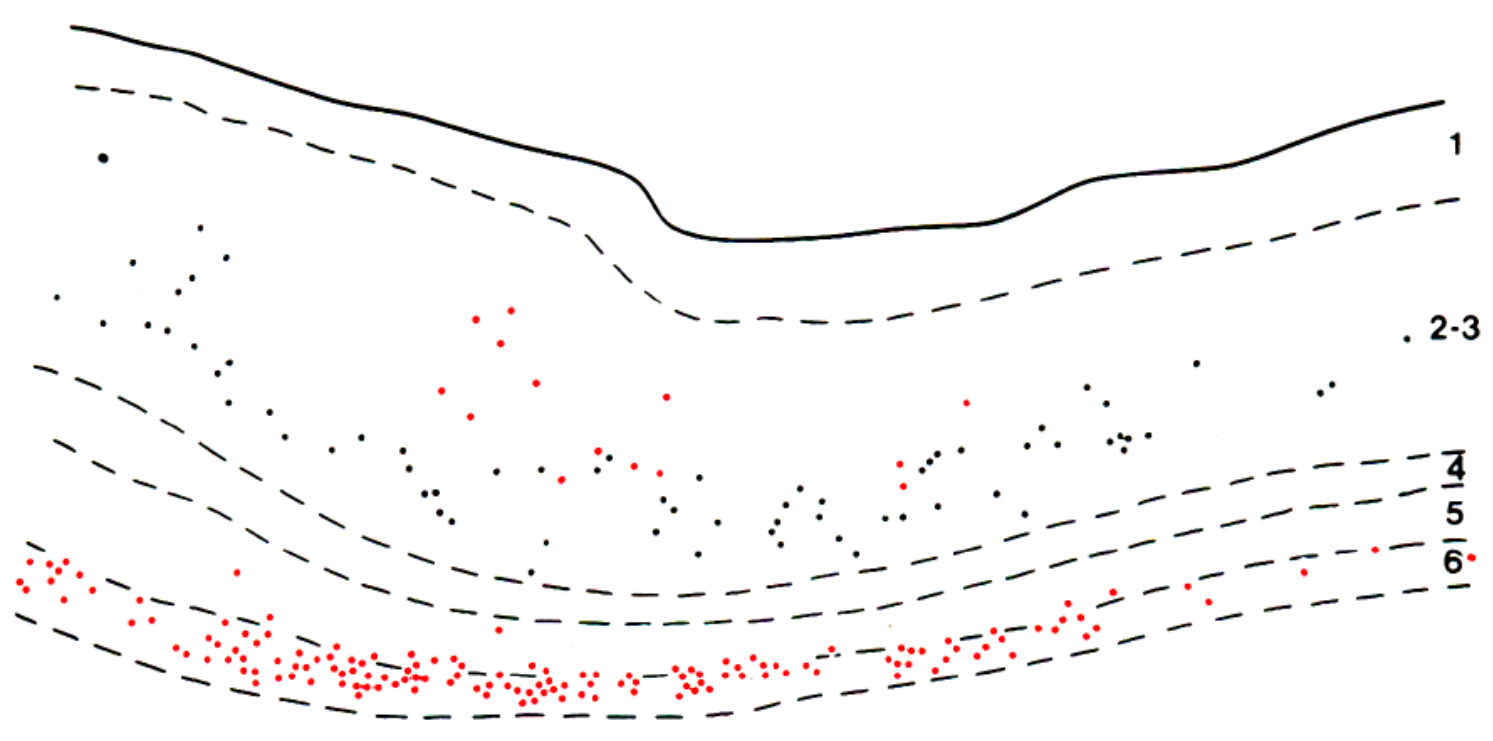

\section{B FETUS (E 122)}

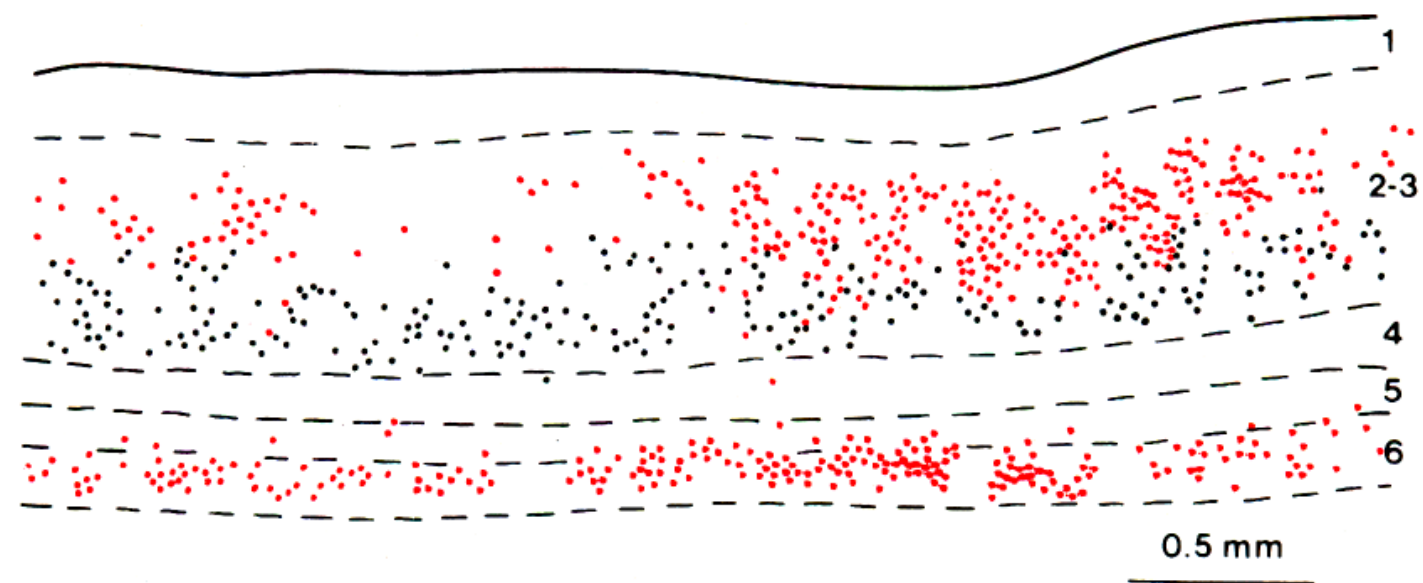

Figure 7. Callosal- and area 17-projecting neurons in the posterior bank of the STS in the adult (top) and E122 fetus (bottom). Both plots were taken from the section showing maximum numbers of area 17-projecting neurons in supragranular layers, which in both adults and fetuses is roughly central to the projection. Note in the adult the paucity of association-projecting neurons in supragranular layers, so that these neurons constitute a transient projection in the fetus (Kennedy et al., 1989). In the fetus, those neurons labeled by the injection in area 17 and that are destined to lose their connection to area 17 display a radial relationship with respect to callosal-projecting neurons similar to that found in more caudally in area V2. Symbols are as in Figure 5.

In the adult, there is a drop in density of labeled area 17projecting neurons as one moves rostrally away from striate cortex (Figs. 5-7). In the fetus, the maximum spatial overlap between callosal- and association-projecting neurons is found in area V2 (Fig. 5), which is in keeping with the fact that the highest proportion of upper-layer area 17-projecting neurons is found in this area (Fig. 4).
The question is whether the adult configuration results from a random elimination of connections or is at least in part obtained by a selective elimination of connections. Selective elimination could effect either callosal or association pathways or both. If elimination of area 17-projecting connections is selective, then those connections originating from the bottom of layer 3 in the fetus would be more likely to be eliminated than those 


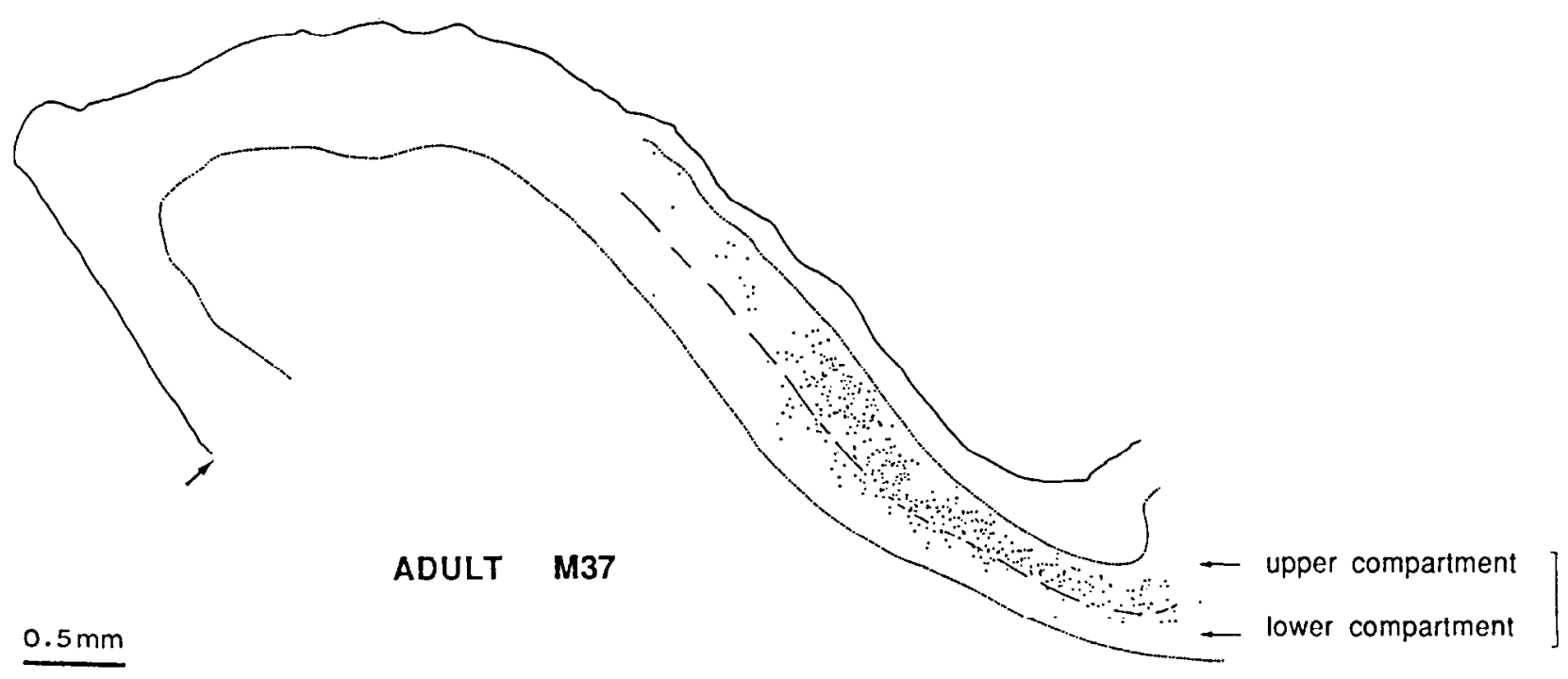

layers $2 / 3$

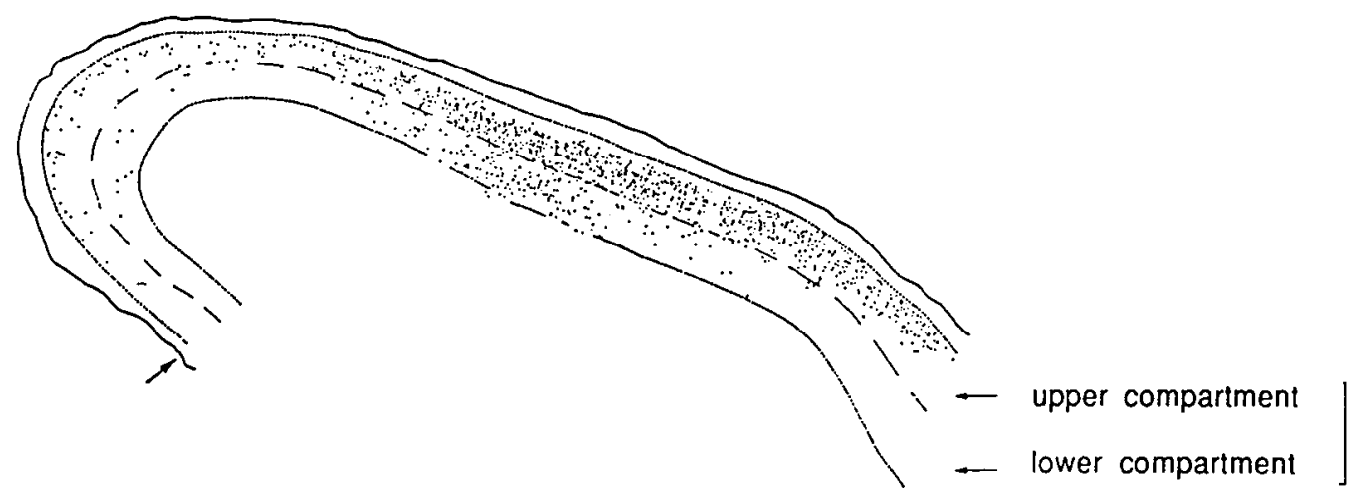

layers $2 / 3$

\section{FETUS BB38}

Figure 8. High-magnification chart of area 17-projecting neurons in supragranular layers in area V2 in the adult (top) and E130 fetus (bottom). Sections have been taken from the center of the projection zone where numbers of supragranular layer neurons are maximum. A $b$ roken line bisects the supragranular layers into upper and lower compartments. Note that in both adult and fetus labeled neurons become more numerous in the lower compartment toward the center of the projection zone.

from the top of layer 2. Conversely, selective elimination of callosal projections means that superficial labeled neurons are more likely to be eliminated than the deeper ones. [Note: By elimination of either callosal- or association-projecting neurons, we are referring to the connections that these neurons make, since what is actually measured is the number of labeled neurons. In fact, axon elimination has frequently been demonstrated in the cortex (Innocenti, 1981; O'Leary et al., 1981; Ivy and Killackey, 1982) and might contribute more frequently to shaping the adult pattern of connectivity than does cell death]. To resolve this issue, it is necessary to make a detailed analysis of the spatial location of the two sets of labeled neurons at different ages. The projection zone located on the posterior bank of the lunate sulcus in the region where area V2 is located has been chosen for this analysis since it shows minimal distortion due to sulcus formation.

In Figure 8 are shown representative plots illustrating the spatial distribution of labeled neurons within the supragranular layers of area V2 in the adult and fetus. The distributions illustrated were obtained from sections returning maximum numbers of labeled neurons and therefore from a plane passing ap- proximately through the center of the projection zone. In both the adult and fetus, labeled neurons are not evenly distributed in the width of the supragranular layers. Figure 8 shows that at the perimeter of the projection zone labeled neurons are predominantly in the upper part of layers $2 / 3$ and become more numerous in the lower part of layers $2 / 3$ toward the center of the projection zone. To characterize precisely the location of labeled neurons within the supragranular layers, we have bisected these layers on high-magnification plots $(80 \times)$ into upper and lower compartments of equal width. This is done by tracing radial segments at regular $550 \mu \mathrm{m}$ intervals and drawing a line perpendicular to them at mid distance between the top of layer 2 and the bottom of layer 3 (see broken lines in Fig. 7).

To quantify the developmental changes in the proportions of labeled neurons in the lower part of layers $2 / 3$, we have calculated the percentage of labeled neurons per section in the lower compartment. In area V2 and at all ages, the percentage per section of area 17-projecting neurons located in the lower compartment of the supragranular layers was found to go from a minimal value in the periphery of the projection zone to a peak value in the region of its center. This is illustrated in Figure 9, 
where the percentage per section of labeled area 17 afferents is shown for a representative adult and fetus. In the adult M44, the percentage goes from a minimum of $4 \%$ in the sections cutting through the peripheral part of the projection zone to a maximum of $12 \%$ in its center. In the fetus BB34, the percentage of labeled neurons in the lower compartment is nearly twice that found in the adult, ranging from $12 \%$ in the periphery to $26.5 \%$ in the central part of the projection zone.

We have the problem of determining a radial distribution from sections that sample cortical layers with a variable angle and where labeled neurons display a nonuniform distribution across the cortical surface. This leads to a variable percentage of labeled neurons being located in the lower compartment of layers $2 / 3$ even in the central two-thirds of the projection zone (fetuses, 3-34\%; neonates, 4-41\%; adults, 1-20\%; Table 2). Since the ranges of percentages in fetuses, neonates, and adults overlap, taking the percentage from one or two sections will not enable one to decide if there is a developmental change in the percentage. Therefore, to characterize the distribution it is necessary to estimate the total number of labeled neurons within each compartment. To do this, we have summed the values obtained on sections taken at $600 \mu \mathrm{m}$ intervals throughout the projection zone.

Taking into account all the injections, the results show that there is a proportional loss during developmental of about half of the labeled area 17-projecting neurons from the lower compartment of the supragranular layers (Table 2). In all, six injections were carried out in four adults. The median value of the percentage of labeled neurons in the lower compartment in the adult was $9.7 \%$ (range, $8.1-11.7 \%$ ). Five injections were made in two fetuses, and the median value in the lower compartment was $19.2 \%$ (range, 13-25\%). A nonparametric statistical test (Mann-Whitney $U$ test, two tailed) showed that the adult and fetal values were significantly different $(p=0.008)$. Five injec-

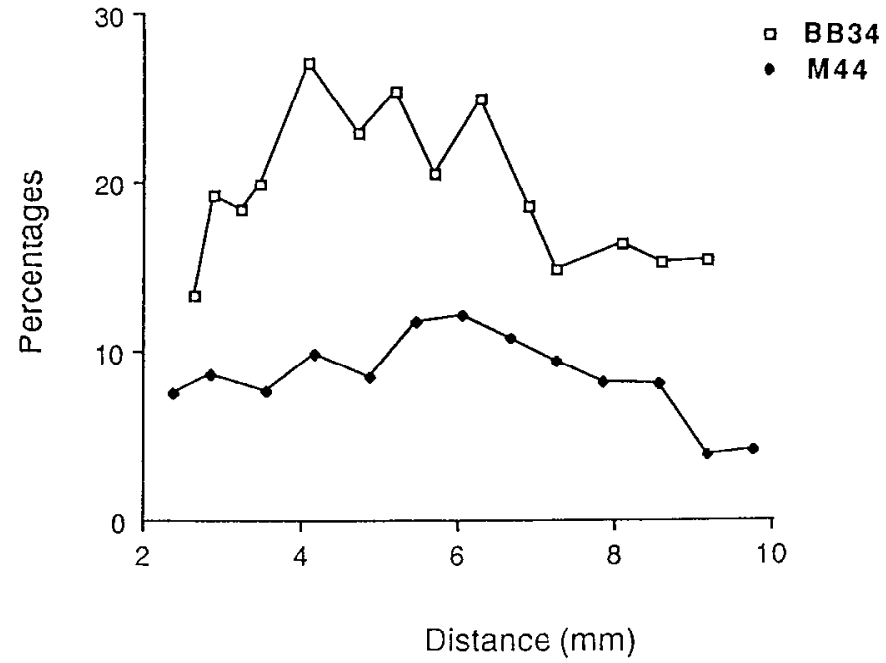

Figure 9. Percentage of area 17-projecting neurons per section in the lower compartment of the supragranular layer in adult (open symbols) and the E122 fetus (solid symbols). Although there is an overall reduction in the proportion of area 17-projecting neurons in the lower compartment during development, in both the adult and fetus this proportion goes from a minimum level in the periphery of the projection zone to a maximum value located toward the center of the projection zone.

tions were carried out in three neonates, and the median value was $16 \%$ (range, 10.6-16.9\%) and was therefore intermediate between adult and fetal values. Statistical comparison (MannWhitney $U$ test, two tailed) showed a significant difference between the neonate and adult population $(p=0.032)$ but not between the neonates and the fetuses $(p=0.1)$. This suggests that the selective elimination of the association projections from the lower part of the supragranular layers is not completed until sometime after birth.

Table 2. Location of labeled neurons in supragranular layers

\begin{tabular}{|c|c|c|c|}
\hline Animals & $\begin{array}{l}\% \text { of area } 17 \text {-projecting neurons } \\
\text { in the bottom half of the } \\
\text { supragranular layers }\end{array}$ & $\begin{array}{l}\text { \% per slide } \\
\text { (range of values) }\end{array}$ & $\begin{array}{l}\% \text { of callosal-projecting neurons } \\
\text { in the upper half of the } \\
\text { supragranular layers }\end{array}$ \\
\hline \multicolumn{4}{|l|}{ Adults } \\
\hline M24 RH DY & 11.1 & $5-20$ & \\
\hline M37 LH DY & 11.7 & $7-17$ & \\
\hline M37 LH FB & 8.1 & $6-15$ & \\
\hline M37 RH DY & 9.7 & $1-18$ & \\
\hline M42 LH DY & 11.5 & $5-20$ & \\
\hline M44 LH DY & 8.9 & $8-12$ & 2.4 \\
\hline \multicolumn{4}{|l|}{ Neonates } \\
\hline BB18 RH DY & 16.0 & $8-31$ & \\
\hline BB18 LH DY & 10.6 & $8-27$ & \\
\hline BB22 RH DY & 16.1 & $5-26$ & \\
\hline BB22 LH DY & 15.0 & $4-41$ & \\
\hline BB43 RH DY & 16.9 & $11-26$ & 3.1 \\
\hline \multicolumn{4}{|l|}{ Fetuses } \\
\hline BB34 LH DY & 20.7 & $15-26$ & 4.6 \\
\hline BB38 LH DY & 25.4 & $9-34$ & \\
\hline BB38 LH FB & 17.7 & $12-22$ & \\
\hline BB38 RH DY & 19.2 & $9-30$ & \\
\hline BB38 RH FB & 13 & $8-22$ & \\
\hline
\end{tabular}


Table 3. Percentages of double-labeled neurons

\begin{tabular}{|c|c|c|c|c|c|}
\hline Animal & & $\begin{array}{l}\text { Posterior bank } \\
\text { of lunate sulcus }\end{array}$ & $\begin{array}{l}\text { Anterior bank } \\
\text { of lunate sulcus }\end{array}$ & Prelunate gyrus & $\begin{array}{l}\text { Posterior bank } \\
\text { of superior } \\
\text { temporal sulcus }\end{array}$ \\
\hline \multicolumn{6}{|l|}{ Fetuses } \\
\hline \multirow[t]{2}{*}{ BB34 } & A & $0.6 \% N=22786$ & $0.6 \% N=6040$ & $0 \% N=656$ & $0.3 \% N=2118$ \\
\hline & $\mathrm{B}$ & $\begin{array}{l}1.1 \% N=12462 \\
(14)\end{array}$ & $\begin{array}{l}0.34 \% N=10770 \\
(14)\end{array}$ & $\begin{array}{l}0 \% N=7207 \\
(14)\end{array}$ & $\begin{array}{l}0.08 \% N=7499 \\
(14)\end{array}$ \\
\hline \multirow[t]{2}{*}{ BB37 } & $A$ & $1.1 \% N=1482$ & - & - & - \\
\hline & $\mathrm{B}$ & $\begin{array}{l}0.8 \% N=2003 \\
(12)\end{array}$ & - & - & - \\
\hline \multirow[t]{2}{*}{ Neonate BB43 } & A & - & $0.15 \% N=5930$ & $0 \% N=237$ & $0.22 \% N=2695$ \\
\hline & $\mathrm{B}$ & - & $\begin{array}{l}0.13 \% N=6908 \\
(14)\end{array}$ & $\begin{array}{l}0 \% N=1420 \\
(14)\end{array}$ & $\begin{array}{l}0.17 \% N=3469 \\
(10)\end{array}$ \\
\hline \multirow[t]{2}{*}{ 4.5 Months BB50 } & A & $0.19 \% N=17315$ & - & - & $0 \% N=9$ \\
\hline & B & $\begin{array}{l}0.95 \% N=3482 \\
(21)\end{array}$ & - & - & $\begin{array}{l}0 \% N=121 \\
(15)\end{array}$ \\
\hline \multicolumn{6}{|l|}{ Adults } \\
\hline \multirow[t]{2}{*}{ M24 } & A & $0.14 \% N=4300$ & - & - & $0 \% N=74$ \\
\hline & B & $\begin{array}{l}1 \% N=579 \\
(13)\end{array}$ & - & - & (9) $0 \% N=66$ \\
\hline \multirow[t]{3}{*}{ M42 } & A & $0.1 \% N=4915$ & $0 \% N=236$ & - & $0 \% N=61$ \\
\hline & B & $0.5 \% N=937$ & $0 \% N=1068$ & - & $0 \% N=497$ \\
\hline & & $(11)$ & $(11)$ & & (11) \\
\hline \multirow[t]{2}{*}{ M44 } & A & $0.03 \% N=15636$ & $0.1 \% N=1786$ & $0 \% N=122$ & $0 \% N=158$ \\
\hline & B & $\begin{array}{l}0.5 \% N=943 \\
\text { (13) }\end{array}$ & $\begin{array}{l}0.06 \% N=3247 \\
(13)\end{array}$ & $\begin{array}{l}0 \% N=174 \\
\text { (13) }\end{array}$ & $\begin{array}{l}0 \% N=3842 \\
\text { (13) }\end{array}$ \\
\hline
\end{tabular}

Numbers in parentheses refer to numbers of sections examined. A, percentages of double-labeled Area V1 afferents; B, percentages of double-labeled callosal afferents.

The radial distribution of callosal neurons, unlike that of the association neurons, undergoes little or no change during development. In both the fetuses and the adults, the vast majority (95-98\%) of callosal neurons were located in the lower compartment of the supragranular layers (Table 2).

Could these changes in the laminar distribution of labeled association neurons in the supragranular layers reflect differences in the laminar location of the injection sites? All injections were relatively large and carried out in a stereotyped fashion (see Materials and Methods). Since the differences between adult and immature populations are statistically significant, a spurious change in laminar distribution would require that injections in the adult population share some characteristic feature distinguishing them from injections in the immature population. Inspection of the injection sites failed to reveal a common feature that distinguishes injection sites in adults from those in either neonates or fetuses. In any case, if differences in the injection sites were to influence labeled neuron distribution, one would expect large variations within each population, which is not the case.

Furthermore, the results are robust in that within each population small differences in the injection sites did not influence the laminar distribution of the retrogradely labeled neurons. For instance, extensive and restricted injections in both sets of animals gave similar percentages (M24 had an extensive area 17 injection and returned a value that was included in the range of values for the restricted injections; see Table 2). In those cases where the injection sites were found to be relatively restricted to subset of layers, the percentage of labeled neurons in the lower compartment of the supragranular layers was included in the overall range. For example, in M37 (right-hemisphere DY injection) the uptake zone did not include the infragranular layers, and yet the percentage of lower compartment neurons $(9.7 \%)$ was included in the overall range $(8.9-11.7 \%)$. In the fetus BB38 (right-hemisphere DY injection), the injection site was more superficial than in other cases and still it returned intermediate values. It would not seem therefore that the distribution of labeled neurons within the supragranular layers is very sensitive to small differences in the location of the injection site.

One aim of the present study was to determine in the fetus whether the spatial relationship of callosal-projecting neurons and the transient population of area 17-projecting cells in upper layers of the superior temporal sulcus differed in any way from that of callosal- and association-projecting neurons elsewhere in extrastriate cortex. Plots of labeled neurons taken from the sections showing maximum counts of supragranular layer neurons showed that callosal-projecting neurons lie deep to the transient area 17-projecting neurons (Fig. 7). The degree of radial segregation of the two neural populations appeared in fact similar to that in area $\mathrm{V} 2$ at the same prenatal age (compare Figs. $5 B, 7 B)$.

\section{Incidence of double labeling}

In the adult, axonal bifurcation to both hemispheres is a rare event. In both fetuses and adults, the majority of double-labeled neurons were in the posterior bank of the lunate sulcus, where there was a tendency for them to be located in the immediate vicinity of the V1/V2 border. The general pattern was that dou- 
ble-labeled ncurons bccame scarcer as one moved away from area 17 , and none of the immature animals showed any double labeling in the prelunate gyrus (Table 3 ).

When expressed as a percentage of the overall labeled population (i.e., of both callosal and association neurons), doublelabeled neurons are approximately five times more numerous in the fetus than in the adult (Meissirel et al., 1990). However, the developmental change in the frequency of double labeling is very different according to whether it is calculated for labeled association or callosal populations. The proportion of doublelabeled neurons in fetuses and adults was similar when expressed as a percentage of callosal neurons because there was a relatively large decrease in the numbers of callosal neurons during development (fetus, $0.8-1.1 \%$; 4.5-month-old infant, $0.95 \%$; adult, 0.5-1.0\%). Numbers of labeled association neurons showed a relatively small decrease during development so that when the proportion of doublc-labclcd ncurons is computed as a percentage of association neurons, the change during development is much greater than that calculated for the callosal population (fetus, 0.6-1.1\%; 4-month-old infant, 0.19\%; adult, 0.03-0.14\%). The 4.5-month-old monkey showed lower levels of double labeling than fetuses, and this was true in all cortical regions examined.

These differences in the frequences of double labeling among the callosal and association populations have a number of theoretical consequences. Although one needs to be cautious not to overinterpret these results given the low rates of double labeling at all ages, it must be pointed out that these values reflect minimum levels of bihemispheric projections (see Discussion). The fact that double-labeled neurons form a constant fraction of callosal neurons at all ages is compatible with the suggestion that bihemispheric-projecting neurons constitute a specific subpopulation of the callosal pathway.

\section{Morphological characteristics of association- and callosal-projecting neurons}

The above results suggest that association and callosal pathways originate from two distinct groups of cortical neurons. However, early in development these two neuronal populations partially share a common laminar origin. Therefore, one would like to know if callosal, association, and double-labeled neurons in the overlap zone of the fetus can be distinguished morphologically on the basis of their soma size (Fig. 10). The mean size of area 17-projecting neurons in the vicinity of the callosal neurons was $45.4 \mu \mathrm{m}^{2}$ and was only marginally larger than the more superficial area 17-projecting cells located outside of the overlap zone (mean surface area, $43.9 \mu \mathrm{m}^{2}$ ). The difference between the two sets of values was not statistically significant. The mean surface area of association ncurons $\left(45.4 \mu \mathrm{m}^{2}\right)$ within the overlap zone was smaller than that of callosal-projecting neurons $\left(55.5 \mu \mathrm{m}^{2}\right)$, which in turn was smaller than that of the double-labeled neurons $\left(63.4 \mu \mathrm{m}^{2}\right)$. Soma sizes of all three populations within the overlap zone were significantly different $(p=0.001)$.

On a morphological basis, one can clearly distinguish association and callosal neurons within the overlap zone at the bottom of layers $2 / 3$. Double-labeled neurons constitute a third distinct group with dimensions that are not intermediate between association and callosal neurons. The fact that the mean size of bihemispheric neurons is situated at the upper limit of the range of callosal neurons suggests that these two groups are more closely related than are bihemispheric and association neurons.

\section{Discussion}

We need to assess critically the relevance of the developmental stages examined. This is of particular importance with regard to those phenomena that do not appear to change during development. In the present study, the laminar location of callosal neurons was found not to change during development. It is known that axogenesis can be a relatively early event and might even take place before neurons have completed their migration (Shoukimas and Hinds, 1978; Schwartz et al., 1991). The earliest age that we examined in the present study is E133, following an injection on E122. The labeled layer 3 neurons would have finished their migration some $10 \mathrm{~d}$ or so prior to our injection (Rakic, 1981) and could have had a more widespread distribution than that which we observe at E133. However, it would not have been possible to measure correctly the radial distribution until after migration of layer 2 neurons is completed and the upper cortical layers are fully formed at E120 (Rakic, 1981). So although we cannot altogether discount the possibility that the distribution of immature callosal neurons might be wider, the present results show that this would occur at most during a 15-20 d period, which, given the duration of corticogenesis in the primate, would be a relatively short-lived period of exuberance.

With respect to the distribution of association neurons, it is unlikely that earlier injections would reveal a more widespread distribution since these connections are not established much before E1 10 (H. Kennedy, unpublished observations). Similarly, it is unlikely that higher levels of double-labeled neurons exist at stages earlier than E122, the age at injection of the youngest fetus examined for double labeling in the present study. At this age, callosal fibers linking the two hemispheres have been in place for $15 \mathrm{~d}$ (Dehay et al., 1988b), and it is only $12 \mathrm{~d}$ since association fibers began to penetrate the cortical gray matter. E122 is therefore about the earliest age when one can retrogradely label large numbers of association and callosal neurons.

It is unlikely that higher levels of bifurcation would be found at developmental stages later than E135, the oldest fetal age examined in the present study (injected at E135, perfused E145). Since double-labeled neurons are largely restricted to the rcgion of overlap of the two populations of single-labeled neurons (present results; Kennedy and Bullier, 1985), an increase in their frequency will imply either an increase in the spatial dimensions of the overlap zone or a change in the ratio of double- and single-labeled neurons within the overlap zone. The first possibility can be discounted since radial overlap can only decrease after E135 as neuron proliferation and migration have already terminated at this age (Rakic, 1974, 1981). The second possibility, that neurons in the overlap zone that at E135 project only to one hemisphere subsequently send an axon to the other hemisphere, seems unlikely. However, LaMantia and Rakic (1990) have shown that the numbers of callosal axons are actually increasing during the period when labeled callosal-projecting neurons in extrastriate visual cortex and the postcentral gyrus are actually disappearing (Killackey and Chalupa, 1986; Dehay et al., 1988b). Similar results arc reported in the rat, where numbers of callosal axons also increase during the period when the number of labeled callosal-projecting neurons is decreasing, leading Gravel et al. (1990) to suggest that the refinement of the pattern of callosal connections, at least in the rat, involves a concomitant growth and selective elimination of axons. 


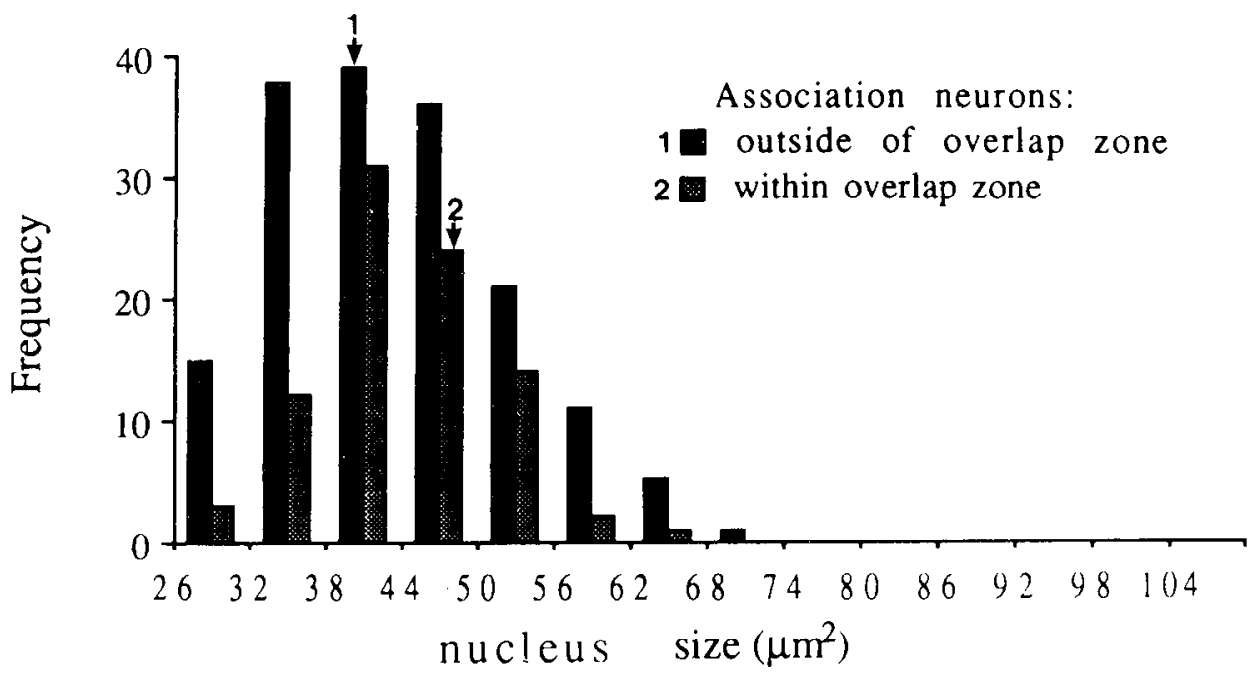

Figure 10. Frequency histogram of the size of labeled cell nuclei. The upper panel shows a comparison of sizes for area 17-projecting neurons located inside and outside the overlap zone. The difference between mean values (numbered arrows) was not statistically significant. The lower panel shows the distributions of sizes of area 17 , callosal, and double-labeled nuclei within the overlap zone. The mean values of all three populations were significantly different.

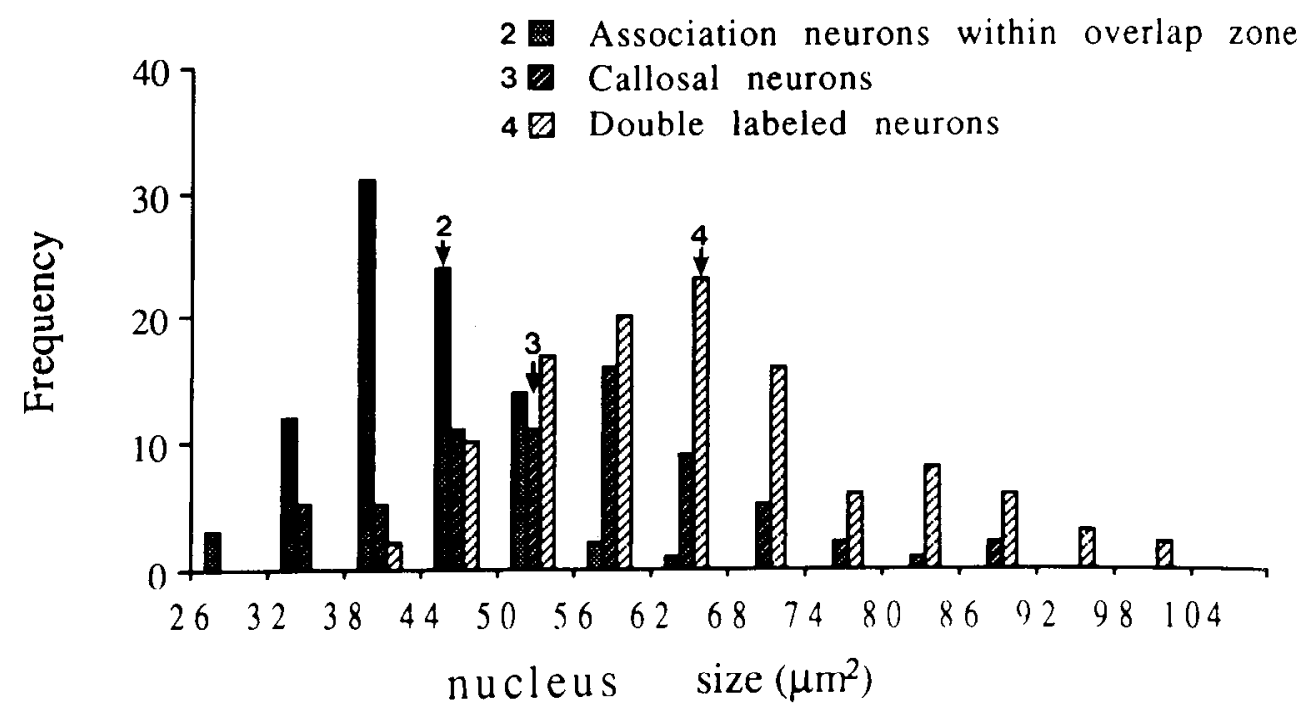

Since the developmental changes in the proportions of double labeling are small, it is imperative to rule out artifactual double labeling in the fetus. Artifactual double labeling would have to occur once retrograde transport is completed as the tracers are injected in separate hemispheres. One possibility is that there is transfer of the dye via gap junctions between callosal and association neurons. Alternatively, it is conceivable that there is leakage of the dyes from single-labeled neurons and secondary pickup by neurons labeled with the complementary dye. If this were to occur to any great extent, the high densities of labeled neurons in the fetal material might lead to artifactual double labeling, which might not occur in the adult due to the greater distances between labeled neurons.

The most pertinent argument against artifactual double labeling is the identification of a feature that is not related to the retrograde transport of the dyes and that distinguishes the two single-labeled populations as well as the double-labeled population. Such an independent feature is provided by the soma size. The fact that the two sets of single-labeled neurons and the double-labeled neurons form three populations that can be clearly distinguished on morphological criteria constitutes a major argument that higher rates of double labeling in the fetus are not artifactual. Association neurons form a population of small-sized neurons, callosal neurons form a population of largesized neurons, and there is little overlap in their range of soma sizes. Double-labeled neurons form a separate group and show the largest soma sizes. If transfer of dye between neurons were responsible for generating double-labeled neurons, their mean soma size would be intermediate between that of association and callosal neurons. The fact that double-labeled neurons form the largest population therefore refutes the possibility of dye transfer between single-labeled neurons.

\section{Area 17 afferents as a general model of association connections}

Before proceeding to consider the significance of the present results for theories of cortical development, we need to consider to what extent the particular sets of connections we have studied 
are representative of callosal and association pathways in general.

Visual responsiveness in extrastriate cortex largely depends on a rostral-directed outflow of activity from area 17 (Mishkin, 1966; Schiller and Malpeli, 1977; Girard and Bullier, 1989; Girard et al., 1991). These connections are reciprocated so that it is possible to distinguish between rostral and caudal directed pathways linking visual areas (Kuypers et al., 1965; Rockland and Pandya, 1979). Rostral- and caudal-directed pathways are characterized by the laminar origin of both the parent cell bodies and the axon terminals (Cragg, 1969; Spatz et al., 1970; Lund et al., 1975; Martinez-Millan and Hollander, 1975; Van Essen and Zeki, 1978; Wong-Riley, 1978; Rockland and Pandya, 1979; Kennedy and Bullier, 1985; Weller and Kaas, 1983; Baizer et al., 1991). In the present study, we have shown that in area V2 there is a selective elimination of caudal-directed projections to area 17. This elimination contributes to establishing the adult pattern where neuron projections to area 17 are concentrated in the upper part of layers $2 / 3$.

By contrast, it is known that in the adult V2, rostral-directed projections to V4 and superior temporal sulcus (STS) are concentrated in the lower part of layer 3 (Rockland and Pandya, 1979; Lund et al., 1981; Fries and Zeki, 1983; Maunsell and Van Essen, 1983; Ungerleider and Desimone, 1986; Shipp and Zeki, 1989; Zeki and Shipp, 1989). This suggests that in the adult there might be a radial segregation of rostral- and caudaldirected association pathways.

Selective elimination of association connections has been documented in cat, where it concerns rostral-directed projections from area 17 to areas 18 and 19 (Bullier et al., 1984c; Price and Blakemore, 1985). Therefore, there is no a priori reason to suppose that selective elimination would not also concern rostraldirected association pathways in primates. If this is the case, it might well concern the more superficial-lying neurons of this pathway and, in this case, will contribute to its radial segregation from caudal-directed pathways.

It has been suggested that caudal- and rostral-directed projections constitute feedforward and feedback pathways linking visual areas occupying different hierarchal positions in the processing of visual information (Rockland and Pandya, 1979; Maunsell and Van Essen, 1983). Callosal connections in area V2 labeled after massive contralateral injections include homotopic projections to the contralateral area V2 as well as heterotopic projections to rostral extrastriate cortex including STS. Therefore, callosal connections in area V2 are heterogeneous in terms of their processing status and include horizontal or intermediate connections between areas occupying equivalent hierarchal status as well as feedforward connections (Kennedy et al., 1986; Kennedy and Dehay, 1988). This means the segregation we have described between callosal and area 17 projections in area V2 is a segregation between a feedback and a feedforward pathway. Could the separation we observe in the present study reflect differences in the supposed processing mode of the two pathways rather than the callosal/association dichotomy? We have some evidence supporting the latter. In STS, many of the callosal connections labeled in the present study are to heterotopic targets that lie caudal to STS and may be assimilated to feedback pathways (Kennedy et al., 1991). Hence, the segregation between area 17-and callosal-projecting neurons that we observe in fetal STS constitutes a separation between two pathways with equivalent processing status.
Developmental changes in the spatial relationships of callosal and association pathways in supragranular layers

The present results show that during development there is a proportional loss of association projections from the supragranular layers. The elimination of area 17 afferents from supragranular layers is not a random process. The radial position of an association neuron determines the probability of the loss of its long-range axon. Therefore, the elimination of connections from layers $2 / 3$ is selective. This radial reorganization of association connections contrasts with callosal connections that show no change in their laminar distribution since at all ages examined they are virtually restricted to the lower part of layers $2 / 3$.

Both the callosal and associative pathways undergo a developmental refinement that contributes to their segregation. However, these two pathways differ in the nature of their refinement both spatially as well as temporally. As we shall show below, these differences have important consequences for the possible role of extrinsic control in the determination of the adult pattern of cortical connectivity.

Whereas the spatial refinement of callosal connections operates almost entirely in the tangential domain, association projections undergo an important radial reorganization. The climination of connections, even if it is a selective process, can result from either intrinsic or extrinsic control (i.e., it can be a preprogrammed event or it can be triggered by environmental cues). To determine the relative contribution of these two types of control, it would be necessary to challenge the normal development of these two pathways by experimentally manipulating the cellular environment (Stent, 1981; McConnell, 1988a). In some cases where a particular category of afferent-projecting neurons has a more widespread tangential distribution in the immature cortex, experimental and genetic manipulations have been shown to impede the acquisition of the normal adult pattern (Shatz, 1977; Innocenti and Frost, 1980; Rhoades et al., 1987; O'Leary and Stanfield, 1989; Koralek and Killackey, 1990). (Note: Those cases where experimental manipulations have failed to influence the normal developmental outcome [e.g., the failure of enucleation to stabilize transient projections of the auditory cortex to the visual cortex in the kitten (Innocenti et al., 1988; C. Dehay, H. Kennedy, and J. Bullier, unpublished observations)] could imply that the refinement in question comes uniquely under intrinsic control or alternatively that the appropriate manipulation has not been performed.) This has also been shown to be true for the callosal connectivity of the monkey extrastriate cortex. Recent results have shown that removal of the peripheral input to the visual cortex subsequent to neuron migration severely perturbs the elimination of callosal connections so that there is a failure to achieve the normal restricted adult pattern of connections (Dehay et al., 1989). This indicates that the tangential pattern of callosal connections is under epigenetic control. The more widespread radial distribution of association projections suggests that extrinsic control might also contribute to the final choice of targets of ipsilateral-projecting ncurons.

The refinement of callosal and association projections occurs according to independent timetables so that these two pathways complete their maturation at different developmental epochs. The adultlike tangential distribution of callosal connections in extrastriate cortex is established in the last month of gestation. 
Its devclopment is partially rcgulatcd by extrinsic signals from the retinas (Dehay et al., 1988b, 1989). The development of association connections is considerably prolonged with respect to the maturation of the callosal pathway and still displays immature features 4.5 months after birth (Kennedy et al., 1990). The relatively late maturation of area 17 cortical afferents could be a developmental strategy ensuring that, like the formation of ocular dominance columns, it occurs during postnatal life while the infant monkey has visual experience. Alternatively, this could be a heterochronicity common to all primate association pathways and might reflect their phylogenetic importance in the emergence of the complexity of the primate brain (Kennedy et al., 1989).

\section{Elimination of bifurcated projections to both cortical hemispheres during development}

During development, there is a reduction of the proportion of neurons in the visual cortex that project to both hemispheres. It should be pointed out that by injecting area 17 we are only labeling a fraction of extrastriate neurons with long-range projections. If one were to inject all the potential ipsilateral targets of a given extrastriate area, one would predict that this would reveal, even in the adult, substantially greater proportions of callosal-projecting neurons with an ipsilateral-projecting collateral.

It is possible to relate changes in proportion of bihemispheric projecting neurons with the segregation of callosal and association pathways. The fact that during development the percentage of double-labeled neurons hardly changes when expressed as a percentage of callosal projections indicates that the probability of loss of an axon for a juvenile single-labeled callosal neuron is no different than for a bihemispheric neuron so that the two pathways show a parallel decrease in frequency. The situation is quite different for the association population. During development the percentage of double-labeled neurons expressed as a percentage of association projections drops by a factor of 10 .

In the adult, double-labeled neurons are largely restricted to the overlap zone (Kennedy and Bullier, 1985; Perkel et al., 1986; Salin et al., 1989; Kaske et al., 1991). It could be, therefore, that the decrease in the proportion of bihemispheric-projecting neurons is merely the consequence of the developmental narrowing of the overlap zone of the two single-labeled populations. This would mean that throughout development a constant fraction of association neurons in the overlap zone would possess an axon collateral projecting to the contralateral hemisphere. One way to test this hypothesis is to examine whether the incidence of double labeling as a percentage of area 17-projecting neurons remains constant in the overlap zone at different ages. In a representative fetus (BB34) and adult (M44), we have computed the frequency of double-labeled neurons as a percentage of association neurons in the lower compartment of layers $2 / 3$ (which approximates the overlap zone). In the fetus, the percentage was $3.7 \%$, compared to $0.3 \%$ in the adult, suggesting that the developmental reduction of the percentage of doublelabeled neurons is not due to the selective elimination of area 17 afferents from the lower part of layers $2 / 3$.

To summarize, callosal and association pathways partially share a common laminar origin. The spatial dimensions of this overlap zone decrease during development. Within the overlap zone, association, callosal, and double-labeled neurons consti- tute three populations with distinctive morphologies. The size and location of the double-labeled neurons within the overlap zone indicate that they are more closely related to the callosal than to the association population. It would seem that the reduction of double-labeled neurons is a selective process largely independent of the narrowing of the radial distribution of the association pathway.

\section{Conclusion}

The timing of the specification of phenotypic expression indicates the possible contribution of extrinsic control on cortical development. The specification of the connectivity of a cortical neuron can occur either relatively early or late in development. For instance, in primates the acallosal nature of area VI is specified precociously, since callosal-projecting neurons are absent from this area throughout ontogeny, while the callosal connectivity of area $\mathrm{V} 2$ is specified late in development, as up to a month before birth this area contains large numbers of callosalprojecting neurons with a diffuse tangential distribution (Dehay et al., 1988b). The present study shows that late specification is also found in the association pathway. One consequence of late specification of neuronal connectivity is that extrinsic or environmental factors are more likely to exert an influence on the final choice of cortical targets. The experimental verification of this possibility involves challenging the developmental fate of cortical neurons (Stent, 1981; McConnell, 1988a). Recent results have shown that removal of the peripheral input to the visual cortex of the monkey subsequent to neuron precursor migration leads to the rescue of numerous transient callosal projections in extrastriate cortex (Dehay et al., 1989), indicating that the tangential pattern of callosal connectivity is under epigenetic control.

The radial distribution of callosal-projecting neurons as well as their incidence of bifurcation to both hemispheres is specified early. Association-projecting neurons, on the other hand, show a relatively late refinement of their cortical lamination. We have suggested elsewhere that the relative timing of cortical development might be quite different in primates and nonprimates (Dehay and Kennedy, 1988; Kennedy et al., 1989). The present results reveal important timing differences in the specification of connectivity among primate cortical neurons. The chronological hierarchy in target specification suggests that the role of environmental factors may differ for different populations of neurons, even within the same cortical layer.

\section{References}

Baizer JS, Ungerleider LS, Desimone R (1991) Organization of visual inputs to the inferior temporal and posterior parietal cortex in macaques. J Neurosci 11:168-190.

Bok ST (1959) Histonomy of the cerebral cortex. Amsterdam: Elsevier.

Bullier J, Kennedy H, Salinger W (1984a) Bifurcation of subcortical afferents to visual areas 17,18 and 19 in the cat cortex. J Comp Neurol 228:309-328.

Bullier J, Kennedy H, Salinger W (1984b) Branching and laminar origin of projections between visual cortical areas in the cat. J Comp Neurol 228:329-341.

Bullier J, Dehay C, Kennedy H (1984c) Axonal bifurcation and cortico-cortical connections in the kitten visual cortex. J Physiol (Lond) 353:22P.

Caviness VS Jr, Rakic P (1978) Mechanisms of cortical development: a view from mutations in mice. In: Annual review of neuroscience (Cowan WM, Hall ZW, Kandel ER, eds), pp 297-326. Palo Alto: Annual Reviews.

Chalupa LM, Lia B (1991) The nasotemporal division of retinal gan- 
glion cclls with crossed and uncrossed projections in the fetal rhesus monkey. J Neurosci 11:191-202.

Condé $F$ (1987) Further studies on the use of the fluorescent tracers fast blue and diamidino yellow: effective uptake area and cellular storage sites. J Neurosci Methods 21:31-43.

Cragg BG (1969) The topography of the afferent projections in the circumstriate visual cortex of the monkey studied by the Nauta method. Vision Res 9:733-747.

Dehay C, Kennedy H (1988) The maturational status of thalamocortical and callosal connections of visual areas V1 and V2 in the newborn monkey. Behav Brain Res 29:237-244.

Dehay C, Kennedy H, Bullier J (1986) Callosal connectivity of areas V1 and V2 in the newborn monkey. J Comp Neurol 254:20-33.

Dehay C, Kennedy H, Bullier J (1988a) Characterization of transient cortical projections from auditory, somatosensory and motor cortices to visual areas 17, 18 and 19 in the kitten. J Comp Neurol 277:6889.

Dehay C, Kennedy H. Bullier J, Berland M (1988b) Absence of interhemispheric connections of area 17 during development in the monkey. Nature 331:348-350.

Dehay C, Horsburgh G, Berland M, Killackey HP, Kennedy H (1989) Maturation and connectivity of the visual cortex in monkey is altered by prenatal removal of retinal input. Nature 337:265-267.

Ferrer JMR, Price DJ, Blakemore C (1988) The organization of corticocortical projections from area 17 to area 18 of the cat's visual cortex. Proc R Soc Lond [Biol] 233:77-98.

Finlay BL, Wikler KC, Sengelaub DR (1987) Regressive events in brain development and scenarios for vertebrate brain development. Brain Behav Evol 30:102-117.

Fries W, Zeki S (1983) The laminar origin of the inputs to the fourth visual complex of macaque monkey cortex. J Physiol (Lond) 340: $51 \mathrm{P}$.

Gattass R, Gross CG, Sandell JH (1981) Visual topography of V2 in the macaque. J Comp Neurol 201:519-539.

Girard P, Bullier J (1989) Visual activity in area V2 during reversible inactivation of area 17 in the macaque monkey. J Neurophysiol 62 : 1287-1302.

Girard P, Salin PA, Bullier J (1991) Visual activity in macaque area V4 depends on area 17 input. Neuroreport 2:69-72.

Gravel C, Sasseville R, Hawkes R (1990) Maturation of the corpus callosum of the rat. II. Influence of thyroid hormones on the number and maturation of axons. J Comp Neurol 291:147-161.

Innocenti GM (1981) Growth and reshaping of axons in the establishment of visual callosal connections. Science 212:824-827.

Innocenti GM (1986) General organization of callosal connections in the cerebral cortex. In: Cerebral cortex, Vol 5 (Jones G, Peters A, eds), pp 291-353. New York: Plenum.

Innocenti GM, Clarke S (1984) The organization of immature callosal projections. J Comp Neurol 230:287-309.

Innocenti GM, Frost DO (1980) The postnatal development of visual callosal connections in the absence of visual experience of the eyes. Exp Brain Res 39:365-375.

Innocenti GM, Berbel P, Clarke S (1988) Development of projections from auditory to visual areas in the cat. J Comp Neurol 272:242259.

Ivy GO, Killackey HP (1981) The ontogeny of the distribution of callosal projection neurons in the rat parietal cortex. J Comp Neurol 195:367-389.

Ivy GO, Killackey HP (1982) Ontogenic changes in the projections of neocortical neurons. J Neurosci 2:735-743.

Jensen KF, Killackey HP (1984) Subcortical projections from ectopic neocortical neurons. Proc Natl Acad Sci USA 81:964-968.

Kaske A, Dick A, Creutzfeldt OD (1991) The local domain for divergence of subcortical afferents to the striate and extrastriate visual cortex in the common marmoset (Callithrix jacchus): a multiple labelling study. Exp Brain Res 84:254-265.

Keizer K, Kuypers HGJM, Huisman AM, Dann O (1983) Diamidino yellow dihydrochloride (DY-2HCL); a new fluorescent retrograde neuronal tracer, which migrates only very slowly out of the cell. Exp Brain Res 51:179-191.

Kennedy H, Bullier J (1985) A double labelling investigation of the afferent connectivity to cortical areas $\mathrm{V} 1$ and $\mathrm{V} 2$ of the macaque monkey. J Neurosci 5:2815-2830.

Kennedy H, Dehay C (1988) Functional implications of the anatom- ical organization of the callosal projections of visual areas V1 and V2 in the macaque monkey. Behav Brain Res 29:225-236.

Kennedy H, Dehay C, Bullier J (1986) The organization of the callosal connections of visual areas V1 and V2 in the monkey. J Comp Neurol 247:398-415.

Kennedy H, Bullier J, Dehay C (1989) Transient projection from the superior temporal sulcus to area 17 in the newborn macaque monkey. Proc Natl Acad Sci USA 86:8093-8097.

Kennedy H, Meissirel C, Dehay C, Berland M, Dumas AM (1990) Remodelling of cortical connections during prenatal development in the monkey. J Physiol (Lond) 430:116P.

Kennedy H, Meissirel C, Dehay C (1991) Callosal pathways in primates and their compliancy to general rules governing the organization of corticocortical connectivity. In: Vision and visual dysfunction, Vol 3 (Cronly-Dillon J, gen ed), Neuroanatomy of the visual pathways and their development (Dreher B, Robinson S, eds), pp 324-359. London: Macmillan.

Killackey HP (1990) Neocortical expansion: an attempt toward relating phylogeny and ontogeny. J Cogn Neurosci 2:1-17.

Killackey HP, Chalupa LM (1986) Ontogenetic change in the distribution of callosal projection neurons in the postcentral gyrus of the fetal rhesus monkey. J Comp Neurol 244:331-348.

Koralek KA, Killackey HP (1990) Callosal projections in rat somatosensory cortex are altered by early removal of afferent input. Proc Natl Acad Sci USA 87:1396-1400.

Kuypers HGJM, Szwarcbart MK, Mishkin M, Rosvold HE (1965) Occipitotemporal corticocortical connections in the rhesus monkey. Exp Neurol 11:245-262.

Kuypers HGJM, Bentivoglio M, Castman-Berrevoets CE, Bahros TB (1980) Double retrograde neuronal labelling through divergent axon collaterals using two fluorescent tracers with the same excitation wavelength which label different features of the cell. Exp Brain Res 40: 383-392.

LaMantia AS, Rakic P (1990) Axon overproduction and elimination in the corpus callosum of the developing rhesus monkey. J Neurosci 10:2156-2175

Lund JS, Lund RD, Hendrickson AE, Bunt AH, Fuchs AF (1975) The origin of efferent pathways from the primary visual cortex of the macaque monkey as shown by retrograde transport of horseradish peroxidase. J Comp Neurol 164:287-304.

Lund JS, Hendrickson AE, Ogren MP, Tobin EA (1981) Anatomical organization of primate visual cortex area VII. J Comp Neurol 202: $19-45$.

Martinez-Millan L, Hollander H (1975) Cortico-cortical projections from striate cortex of the squirrel monkey (Saimiri sciureus). A radioautographic study. Brain Res 83:405-417.

Maunsell JHR, Van Essen DC (1983) The connections of the middle temporal visual area (MT) and their relationship to a cortical hierarchy in the macaque monkey. $\mathrm{J}$ Neurosci 3:2563-2568.

McConnell SK (1988a) Development and decision making in the mammalian cerebral cortex. Brain Res Rev 13:1-23

McConnell SK (1988b) Fates of visual cortical neurons in the ferret after isochronic and heterochronic transplantation. J Neurosci 8:945974.

Meissirel C, Dehay C, Berland M, Kennedy H (1990) Incidence of visual cortical neurons which have axon collaterals projecting to both cerebral hemispheres during prenatal primate development. Dev Brain Res 56:123-127.

Mishkin M (1966) Visual mechanisms beyond the striate cortex. In: Frontiers in physiological psychobiology (Russell R, ed), pp 93-119. New York: Academic.

Olavarria JC, Van Sluyters RC (1985) Organization and postnatal development of callosal connections in the visual cortex of the rat. $J$ Comp Neurol 239:1-26.

O'Leary DDM (1989) Do cortical areas emerge from a protocortex? Trends Neurosci 12:400-406.

O'Leary DDM, Stanfield BB (1989) Selective elimination of axons extended by developing cortical neurons is dependent on regional locale: experiments utilizing fetal transplants. J Neurosci 9:22302246.

O'Leary DDM, Stanfield BB, Cowan WM (1981) Evidence that the early postnatal restriction of the cells of origin of the callosal projection is due to the elimination of axonal collaterals rather than to the death of neurons. Dev Brain Res 1:607-617. 
Perkel DJ, Bullier J, Kennedy H (1986) Topography of afferent connectivity of area 17 in the macaque monkey: a double-labeling study. J Comp Neurol 253:374-402.

Price DJ, Blakemore C (1985) Regressive events in the postnatal development of association projections in the visual cortex. Nature 316 : 721-724.

Rakic P (1974) Neurons in rhesus monkey visual cortex: systematic relation between time of origin and eventual disposition. Science 183: 425-427.

Rakic P (1981) Developmental events leading to laminar and areal organization of the neocortex. In: The organization of the cerebral cortex (Schmitt FO, Worden FG, Edelman G, Dennis SG, eds), pp 7-28. Cambridge, MA: MIT Press.

Rhoades RW, Fish SE, Mooney RD, Chiaia NL (1987) Distribution of visual callosal projection neurons in hamsters subjected to transection of the optic radiations on the day of birth. Dev Brain Res 32: 217-232.

Rockland KS, Pandya DN (1979) Laminar origins and terminations of cortical connections to the occipital lobe in the rhesus monkey. Brain Res 179:3-20.

Salin PA, Bullier J, Kennedy H (1989) Convergence and divergence in the afferent projections to cat area 17. J Comp Neurol 283:486512.

Schiller PH, Malpeli JG (1977) The effect of striate cortex cooling on area 18 cells in the monkey. Brain Res 126:366-369.

Schwartz ML, Rakic P, Goldman-Rakic PS (1991) Early phenotype expression of cortical neurons: evidence that a subclass of migrating neurons have callosal axons. Proc Natl Acad Sci USA 88:1354-1358.
Shatz CJ (1977) Anatomy of intrahemispheric connections in the visual system of Boston siamese and ordinary cats. J Comp Neurol 173:497-518.

Shipp S, Zeki S (1989) The organization of connections between areas V5 and V2 in macaque visual cortex. Eur J Neurosci 1:333-359.

Shoukimas GM, Hinds JW (1978) The development of the cerebral cortex in the embryonic mouse: an electron microscopic serial section analysis. J Comp Neurol 179:795-830.

Spatz WB, Tigges J, Tigges M (1970) Subcortical projections, cortical associations and some intrinsic interlaminar connections of the striate cortex in the squirrel monkey (Saimiri). J Comp Neurol 140:155174.

Stent GS (1981) Strength and weakness of the genetic approach to the development of the nervous system. Annu Rev Neurosci 4:163-193.

Ungerleider LG, Desimone R (1986) Cortical connections of visual area MT in the macaque monkey. J Comp Neurol 248:190-222.

Van Essen DC, Zeki S (1978) The topologic organization of rhesus monkey prestriate cortex. J Physiol (Lond) 277:193-226.

Weller RE, Kaas JH (1983) Retinotopic patterns of connections of visual area 17 with visual areas VII and MT in macaque monkey. $J$ Comp Neurol 220:253-279.

Wong-Riley M (1978) Reciprocal connections between striate and prestriate cortex in the squirrel monkey as demonstrated by combined peroxidase histochemistry and autoradiography. Brain Res 147:159164.

Zeki S, Shipp S (1989) Modular connections between areas V2 and V4 of monkey visual cortex. Eur J Neurosci 1:494-506. 